\title{
Enolase 1 stimulates glycolysis to promote chemoresistance in gastric cancer
}

\author{
Xiaoling Qian ${ }^{1, *}$, Wenxia $X u^{1, *}$, Jinye $X u^{1}$, Qiqi Shi ${ }^{1}$, Jiaqiu $\mathbf{L i}^{2}$, Yu Weng ${ }^{3}$, Zhinong \\ Jiang ${ }^{4}$, Lifeng Feng ${ }^{1}$, Xian Wang ${ }^{2}$, Jianwei Zhou ${ }^{5}$ and Hongchuan Jin ${ }^{1}$ \\ 'Laboratory of Cancer Biology, Key Lab of Biotherapy in Zhejiang, Sir Run Run Shaw Hospital, Medical School of Zhejiang \\ University, Zhejiang, China \\ ${ }^{2}$ Department of Medical Oncology, Sir Run Run Shaw Hospital, Medical School of Zhejiang University, Zhejiang, China \\ ${ }^{3}$ Department of Clinical Medicine, Sir Run Run Shaw Hospital, Medical School of Zhejiang University, Zhejiang, China \\ ${ }^{4}$ Department of Pathology, Sir Run Run Shaw Hospital, Medical School of Zhejiang University, Zhejiang, China \\ ${ }^{5}$ Department of Molecular Cell Biology and Toxicology, School of Public Health, Nanjing Medical University, Nanjing, China \\ *These authors contributed equally to this work
}

Correspondence to: Hongchuan Jin, email: jinhc@zju.edu.cn

Keywords: enolase 1, cisplatin-resistance, glycolysis, gastric cancer, miRNA-22

Received: February 07, 2017 Accepted: April 27, $2017 \quad$ Published: May 15, 2017

Copyright: Qian et al. This is an open-access article distributed under the terms of the Creative Commons Attribution License 3.0 (CC BY 3.0), which permits unrestricted use, distribution, and reproduction in any medium, provided the original author and source are credited.

\section{ABSTRACT}

Chemotherapy is the major choice for the cancer treatment of early and advanced stages. However, intrinsic or acquired drug resistance significantly restricts the clinical efficacy of chemotherapy. It is critical to develop novel approaches to detect and overcome drug resistance. In this study, we demonstrated that accelerated glycolysis played a pivotal role in both intrinsic and acquired cisplatin-resistance of gastric cancer cells. The metabolic reprogramming of cisplatin-resistant cells was characterized by increased glycolysis dependence. Inhibition of glycolysis with glucose starvation or 2-Deoxy-D-glucose (2-DG) treatment significantly reversed drug resistance. By proteomic screening, we found the increased expression of the glycolytic enzyme Enolase 1 (ENO1) in cisplatin-resistant gastric cancer cells. Depletion of ENO1 by siRNA significantly reduced glycolysis and reversed drug resistance. Moreover, the increased expression of ENO1 was attributed to the down-regulation of ENO1-targeting miR-22, rather than activated gene transcriptional or prolonged protein stability. Finally, the elevated levels of ENO1 proteins were associated with the shorter overall survival of gastric cancer patients. In conclusion, ENO1 is a novel biomarker to predict drug resistance and overall prognosis in gastric cancer. Targeting ENO1 by chemical inhibitors or up-regulating miR-22 could be valuable to overcome drug resistance.

\section{INTRODUCTION}

Gastric cancer is one of the most prevalent cancers worldwide, especially in East Asia [1]. Chemotherapy in the form of neo-adjuvant or adjuvant therapy is the dominant treatment for most of the gastric cancers. Despite of the rapid development of new therapeutic drugs such as target therapy drugs, cisplatin (DDP) remains one of the most important drugs used in the treatment of gastric cancer. Unfortunately, drug resistance poses a major challenge to benefit gastric cancer patients from DDP-based chemotherapy.
Multiple mechanisms participate in DDP resistance, including increased drug efflux, drug inactivation, enhanced DNA damage repair, active survival signaling pathway and evasion of apoptosis [2]. Recently, the relevance of metabolic reprogramming to drug resistance received much attention [3, 4]. As one of major hallmarks of cancer cells, accelerated aerobic glycolysis contributes to DDP resistance in various cancers such as cervical cancer and lung cancer [5-11]. Although aerobic glycolysis produces less ATP per molecule of glucose than oxidative phosphorylation (OXPHOS), it can confer many selective advantages. For 
example, the ATP generation rate of glycolysis is almost 100 times faster than that of OXPHOS. By consuming more glucose, sufficient ATP could be produced rapidly from glycolysis [12]. In addition, intermediate products during glycolysis can be used as materials for the biosynthesis of macromolecules indispensable for cancer proliferation and growth, like nicotinamide adenine dinucleotide phosphate (NADPH), lipids and nucleic acids. Moreover, NADPH is instrumental to maintain sufficient levels of reduced forms of glutathione (GSH) to antagonize oxidative stress produced by DDP. Meanwhile, glycolysis can also enable cancer cells to reduce ROS generation by limiting the pyruvate flux into mitochondrial respiration, and thus acquire resistance to apoptosis or even promote metastasis [13-15].

To explore the mechanism of drug resistance in gastric cancers, we employed BGC823/DDP with acquired resistance and MGC803 intrinsically resistant to cisplatin [16]. We showed that increased glucose uptake and enhanced aerobic glycolysis occurred in gastric cancer cells with intrinsic or acquired resistance to DDP. Inhibition of glycolysis suppressed cell proliferation and reversed drug resistance. The enhanced glycolysis in drug resistance was caused by increased ENO1 expression resulted from the downregulation of miR-22. Overexpression of ENO1 or down-regulation of miR-22 enhanced glycolysis and promoted cisplatin-resistance. Meanwhile, depletion of ENO1 or up-regulation of miR-22 repressed glycolysis and restored cisplatin sensitivity. Therefore, targeting ENO1 or up-regulating miR-22 could be valuable to overcome drug resistance.

\section{RESULTS}

\section{Glycolysis was enhanced in cisplatin resistant gastric cancer cells}

To explore molecular mechanisms responsible for drug resistance in gastric cancer, we employed BGC823/ DDP with acquired resistance and MGC803 intrinsically resistant to cisplatin [16]. As shown in Figure 1A, there were more survived BGC823/DDP and MGC803 cells when compared with BGC823 cells upon treatment with $0.8 \mu \mathrm{g} / \mathrm{ml}$ of cisplatin. Since nutrient or energy metabolism has been reported to contribute to drug resistance [17-19], we compared glucose consumption in these cells. Both BGC823/DDP and MGC803 cells consumed more glucose than BGC823 cells (Figure 1B and 1C). Consistent with increased glucose consumption, there were more glycolysis metabolic products such as pyruvic acid and lactic acid produced in BGC823/DDP and MGC803 cells than BGC823 cells (Figure 1D, 1E, 1F and $1 \mathrm{G}$ ). Taken together, these data demonstrated that the glycolysis was enhanced in cisplatin resistant gastric cancer cells.

\section{Inhibition of glycolysis reversed cisplatin resistance}

Glycolysis provided metabolic products and energy for cell survival. To clarify the relevance of enhanced glycolysis to drug resistance, we applied glucose deprivation or 2-Deoxy-D-glucose (2-DG), the analogue of glucose as a competitive glycolytic inhibitor. Firstly, we found that BGC823/DDP and MGC803 cells were more sensitive to glucose deprivation than BGC823 cells (Figure 2A and 2B). Similarly, they were more sensitive to 2-DG treatment (Figure 2C and 2D). These results indicated that chemo-resistant cells were dependent more on glycolysis for survival.

Next, we investigated the effect of glycolysis inhibition on cisplatin resistance. We found that glucose deprivation markedly reversed cisplatin resistance in both BGC823/ DDP and MGC803 cells (Figure 2E and 2G). Furthermore, 2-DG treatment also increased sensitivity to cisplatin in BGC823/DDP and MGC803 cells (Figure $2 \mathrm{~F}$ and $2 \mathrm{H}$ ). Both cleaved caspase- 3 and cleaved PARP1 proteins were increased in glucose deprived or 2-DG-treated BGC823/ DDP cells after cisplatin use (Figure 3A and 3B). Similarly, glucose deprivation or 2-DG treatment enhanced cisplatininduced cleavage of caspase-3 and PARP1 in MGC 803 cells (Figure 3C and 3D). The Annexin V/PI detection showed that apoptotic cells were apparently increased induced by cisplatin in glucose deprived or 2-DG treatment of BGC823/ DDP and MGC803 cells (Figure 3E and 3F). In summary, inhibition of enhanced glycolysis could reverse cisplatin resistance.

\section{Cisplatin-resistant cells up-regulated ENO1 to enhance glycolysis}

To identify potential mechanisms underlying enhanced glycolysis and chemoresistance, we employed two-dimensional electrophoresis (2-DE) combined with MALDI-TOF MS to discover the proteomic differences between BGC823 and BGC823/DDP cells [16]. Among 40 identified differential spots, ENO1 was detected in BGC823/DDP cells but not in BGC823 cells (Figure 4A). Western blotting analysis further confirmed that ENO1 was significantly overexpressed in BGC823/DDP and MGC803 cells compared with BGC823 cells (Figure 4B). Since ENO1 was a key enzyme in glycolysis to catalyze 2-phosphoglycerate to phosphoenolpyruvate (Figure 4C), we wondered whether it was relevant to enhanced glycolysis and chemoresistance.

First, we compared changes in glycolysis in BGC823/DDP and MGC803 cells before and after ENO1 knockdown. After transient silencing of ENO1, the glucose consumption was decreased, especially in BGC823/DDP cells (Figure 4D). Consistently, the production of pyruvic 
acid, lactic acid and ATP were significantly decreased after ENO1 knockdown (Figure 4E, 4F and 4G). In conclusion, the increased ENO1 expression enhanced glycolysis in drug-resistant gastric cancer cells.

\section{ENO1 knockdown increased sensitivity to cisplatin}

Then we investigated the impact of ENO1 on cisplatin resistance. Upon ENO1 knockdown, cisplatin sensitivities in BGC823/DDP and MGC803 cells were significantly increased (Figure 5A and 5B). Such increases in drug sensitivities were accompanied with the activation of cell apoptosis, as evidenced by Annexin V and PI staining (Figure 5C and 5D) as well as increased cleavage of caspase-3 and PARP1 by Western blot (Figure 5E and 5F). The ENO1 knockdown efficiency was shown by QPCR (Figure 5G). In summary, these data suggested that the increased expression of key glycolysis catalytic enzyme ENO1 contributed to cisplatin resistance.

\section{Overexpression of ENO1 in cisplatin-sensitive cells induced cisplatin-resistance by glycolysis promotion}

Then we explored the influence of ENO1 on cisplatinsensitive gastric cells. Once ENO1 was overexpressed in BGC823 cells, the cleavage of caspase-3 and PARP1 were decreased and less viability inhibition occurred after cisplatin treatment (Figure 6A and 6B). Consistently, the consumption of glucose and the production of pyruvic acid and lactic acid were significantly increased (Figure 6C), indicating that ENO1 induced cisplatin-resistance by promoting glycolysis.

\section{MicroRNA-22 targeted ENO1 mRNA}

To clarify the regulation of ENO1 in cisplatinresistant cells, we determined the mRNA level of ENO1. Real-time quantitative RT-PCR showed slightly decreased level of mRNA in resistant cells (Figure 7A). In addition, there were no changes in the protein half-lives of ENO1 in BGC823 and BGC823/DDP cells (Figure 7B), indicating that the increased expression of ENO1 in drug resistance was not attributed to the enhanced transcription of ENO1 gene or prolonged stability of ENO1 protein. Therefore, we hypothesized that microRNAs (miRNA) might be involved in the regulation of ENO1. Based on on-line prediction (www.microRNA.org), we chose the highly-conserved microRNA with the highest mirSVR score, miR-22, for further investigations. Indeed, miR-22 was down-regulated in both resistant cells (Figure 7C). Moreover, miR-22 mimics reduced ENO1 protein expression in BGC823/DDP and MGC803 cells (Figure 7D), while miR-22 inhibitor significantly upregulated ENO1 in BGC823 cells (Figure 7D). The 3'-UTR of the ENO1 mRNA with a complementary binding site for miR-22 was cloned into the luciferase
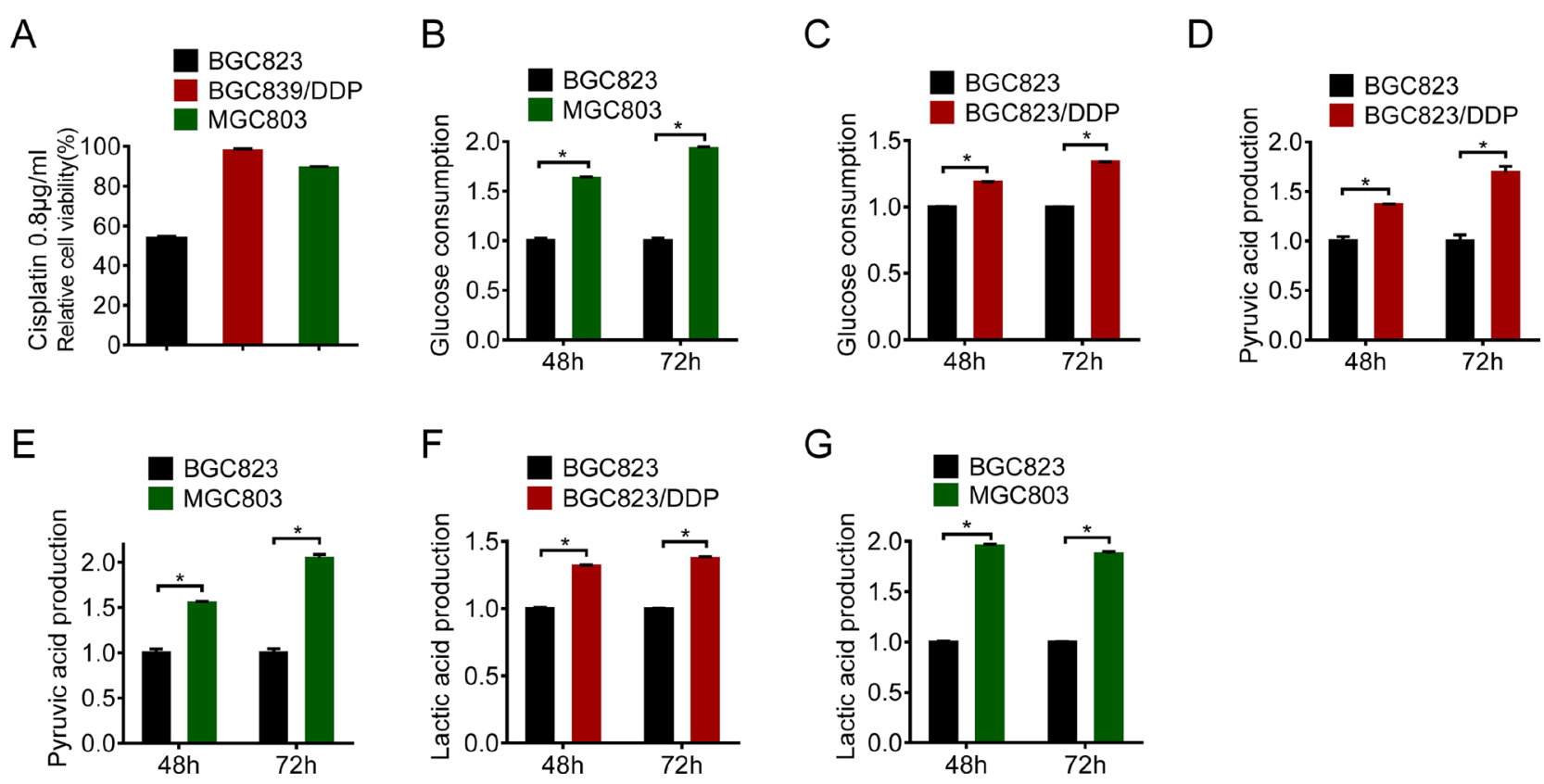

Figure 1: Glycolysis was enhanced in cisplatin resistant gastric cancer cells. (A) Cell viability was assessed by MTS assay through cisplatin treatment $(0.8 \mu \mathrm{g} / \mathrm{ml})$ of BGC823, BGC823/DDP and MGC803 cells for $24 \mathrm{~h}$. (B-C) Glucose consumption was measured between BGC823 and BGC823/DDP, BGC823 and MGC803. The fold changes were normalized by BGC823 glucose consumption $\left(\mu \mathrm{mol} / 10^{6}\right.$ cells). Pyruvic acid production $(\mathbf{D}-\mathbf{E})$ and lactic acid production $(\mathbf{F}-\mathbf{G})$ were analyzed according to instructions. The fold changes were normalized by BGC 823 acid production ( $\mu \mathrm{mol} / 10^{6}$ cells). Results are from representative experiments in triplicate and shown as the mean \pm S.D. ${ }^{*} p<0.05$. 
vector (Figure 7E, left panel). And then we constructed a mutant plasmid which contained point mutations within the miR-22 binding site. Importantly, miR-22 mimics markedly repressed the luciferase reporter activity driven by the wild-type ENO1 3'-UTR while the luciferase expression of mutant plasmid was not affected by miR-22 mimics (Figure 7E, right panel), indicating that ENO1 was a bona fide target of miR-22. Then we analyzed the influence of miR-22 on glycolysis. The consumption of glucose as well as the production of pyruvic acid and lactic acid were increased in BGC 823 cells after transfection of miR-22 inhibitor (Figure 7F). In contrast, consumption of glucose and the production of pyruvic acid and lactic acid were reduced by miR-22 mimic in BGC823/DDP cells. Taken together, these results suggested that miR-22 was responsible for the overexpression of ENO1 protein
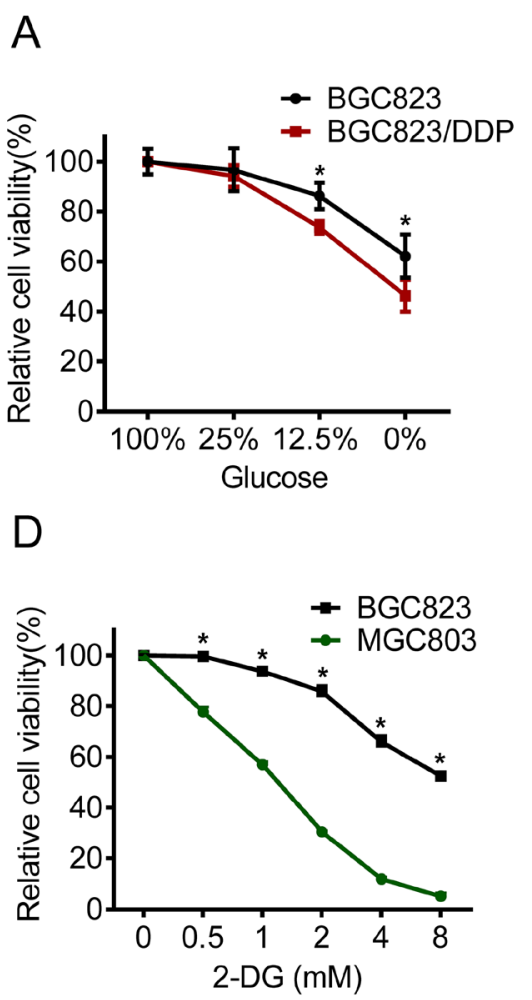

G

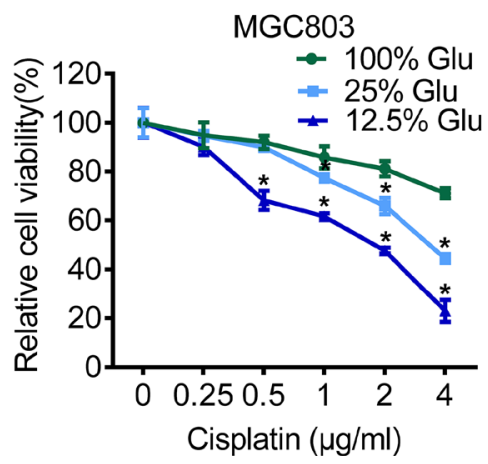

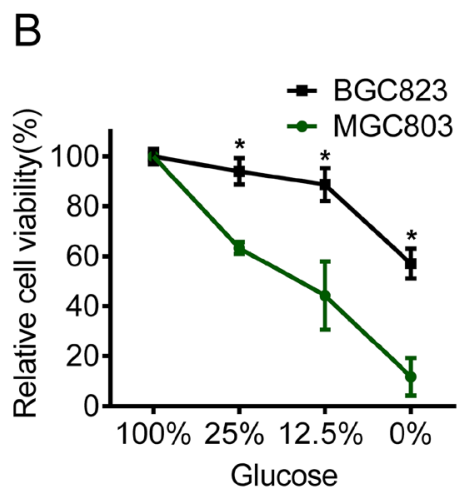

$\mathrm{E}$

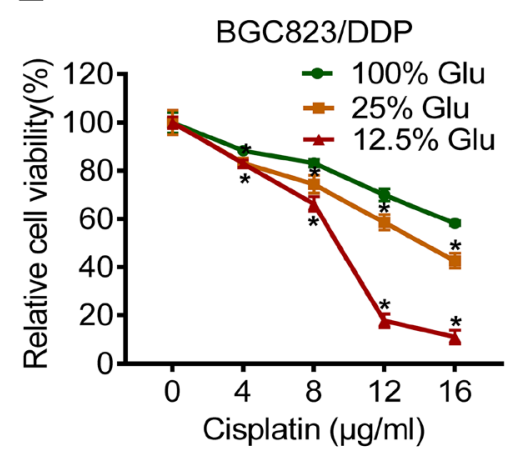

$\mathrm{H}$

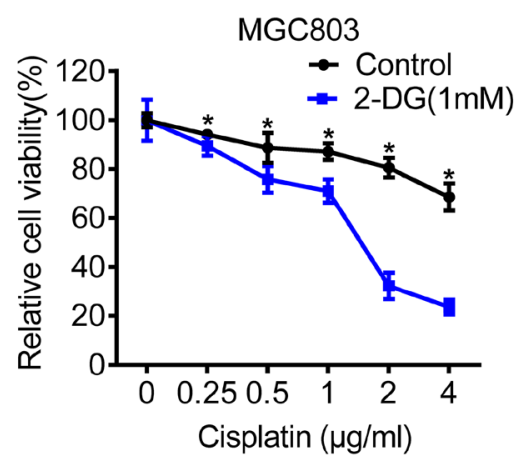

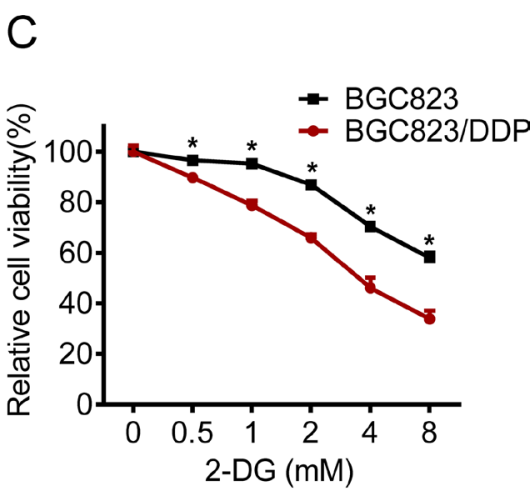

$\mathrm{F}$

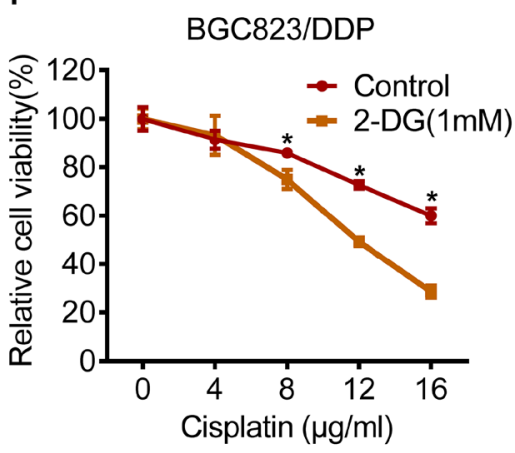

Figure 2: Inhibition of glycolysis reversed cisplatin resistance. (A-B) BGC823, BGC823/DDP and MGC803 cells were cultured in different glucose concentrations of $0 \%, 12.5 \%, 25 \%$ and $100 \%$ for $48 \mathrm{~h}$. Cell viability was assessed by MTS assay. (C-D) 2-DG was added at concentrations of $0 \mathrm{mM}, 0.5 \mathrm{mM}, 1 \mathrm{mM}, 2 \mathrm{mM}, 4 \mathrm{mM}$ and $8 \mathrm{mM}$ for $48 \mathrm{~h}$ and the cell viability was measured by MTS. (E) Glucose was added with concentrations of $12.5 \%, 25 \%$ or $100 \%$ for $48 \mathrm{~h}$ and during the last $24 \mathrm{~h}$ BGC823/DDP cells were exposed to $0 \mu \mathrm{g} / \mathrm{ml}$, $4 \mu \mathrm{g} / \mathrm{ml}, 8 \mu \mathrm{g} / \mathrm{ml}, 12 \mu \mathrm{g} / \mathrm{ml}$ and $16 \mu \mathrm{g} / \mathrm{ml}$ cisplatin. The cell viability was measured by MTS. (F) BGC823/DDP cells were cultured in $1 \mathrm{mM}$ 2-DG for $48 \mathrm{~h}$ and added by $0 \mu \mathrm{g} / \mathrm{ml}, 4 \mu \mathrm{g} / \mathrm{ml}, 8 \mu \mathrm{g} / \mathrm{ml}, 12 \mu \mathrm{g} / \mathrm{ml}$ and $16 \mu \mathrm{g} / \mathrm{ml}$ cisplatin for the last $24 \mathrm{~h}$. The cell viability was measured by MTS. (G) Glucose was supplemented with concentrations of $12.5 \%, 25 \%$ and $100 \%$ for $48 \mathrm{~h}$ and during the last $24 \mathrm{~h}$ MGC 803 cells were exposed to $0 \mu \mathrm{g} / \mathrm{ml}, 0.25 \mu \mathrm{g} / \mathrm{ml}, 0.5 \mu \mathrm{g} / \mathrm{ml}, 1 \mu \mathrm{g} / \mathrm{ml}, 2 \mu \mathrm{g} / \mathrm{ml}$ and $4 \mu \mathrm{g} / \mathrm{ml}$ cisplatin, finally, cell survival was determined by MTS. (H) MGC803 cells were cultured in $1 \mathrm{mM} 2$-DG for $48 \mathrm{~h}$ and added by $0 \mu \mathrm{g} / \mathrm{ml}, 0.25 \mu \mathrm{g} / \mathrm{ml}, 0.5 \mu \mathrm{g} / \mathrm{ml}, 1 \mu \mathrm{g} / \mathrm{ml}, 2 \mu \mathrm{g} / \mathrm{ml} \mathrm{and} 4 \mu \mathrm{g} / \mathrm{ml}$ cisplatin for the last $24 \mathrm{~h}$. The cell viability was measured by MTS. Results are from representative experiments in triplicate and shown as the mean \pm S.D. $* p<0.05$. 
A

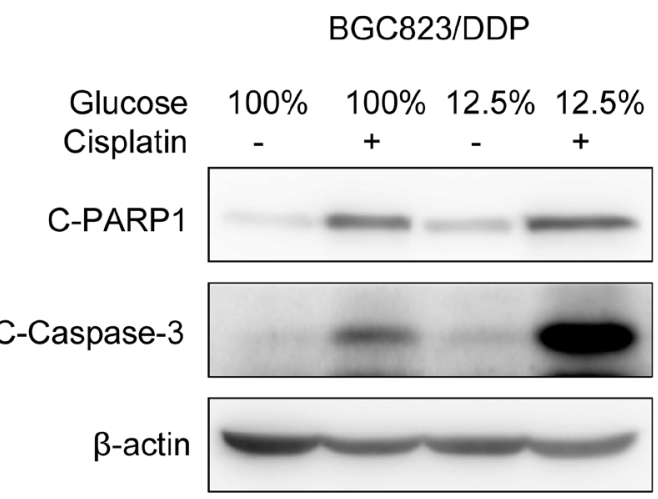

E

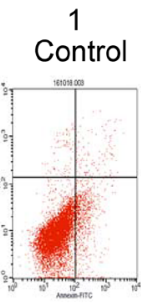

C

MGC803

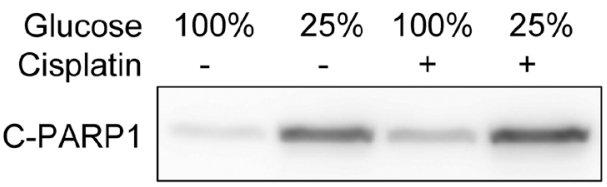

C-Caspase-3

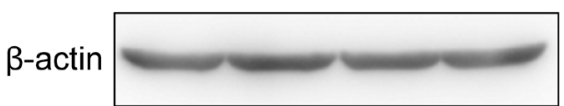

B

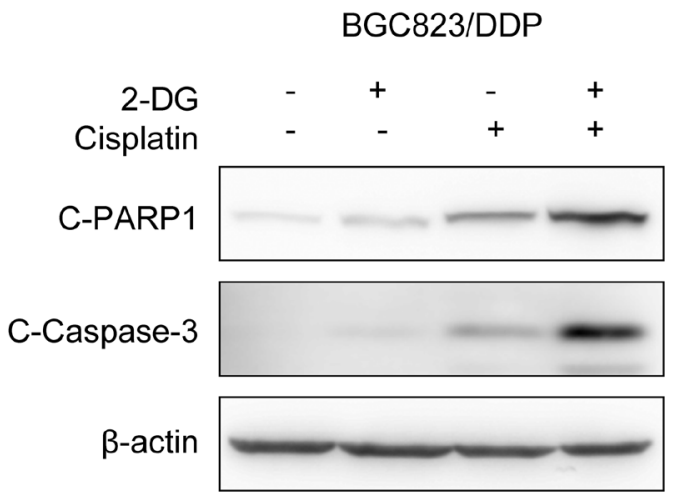

D

MGC803

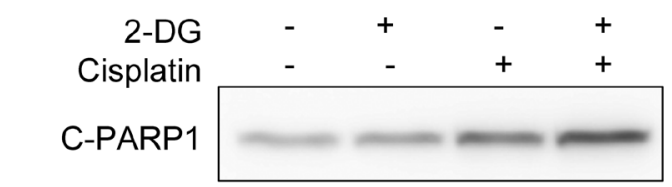

C-Caspase-3

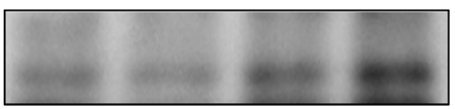

$\beta$-actin

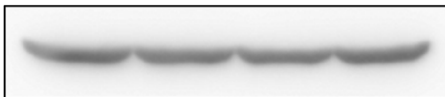

Cisplatin
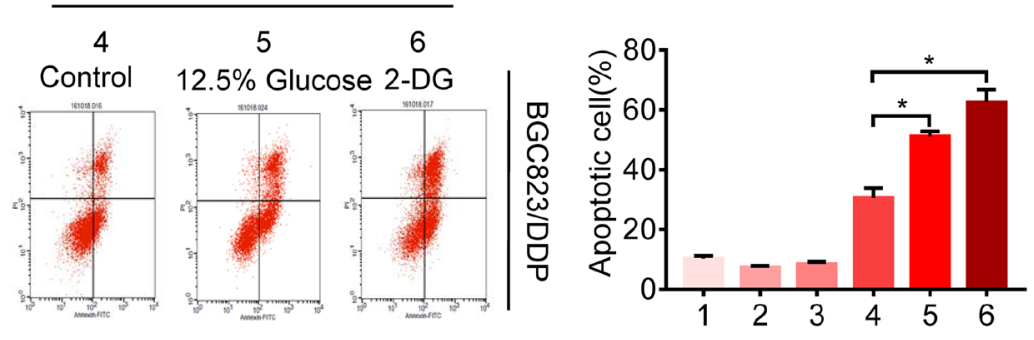

F

Cisplatin
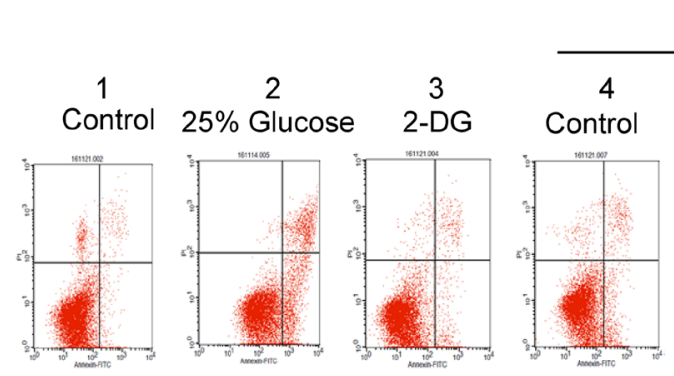

Figure 3: Inhibition of glycolysis reversed cisplatin resistance. (A) The BGC823/DDP cells were exposed to $12.5 \%$ and $100 \%$ of glucose for $48 \mathrm{~h}$ with $8 \mu \mathrm{g} / \mathrm{ml}$ cisplatin exposure for the last $24 \mathrm{~h}$. C-PARP1 and c-Caspase-3 were detected by Western blotting. $\beta$-actin served as loading control. (B) BGC823/DDP cells were treated with $2.5 \mathrm{mM} 2-\mathrm{DG}$ for $48 \mathrm{~h}$ and $8 \mu \mathrm{g} / \mathrm{ml}$ cisplatin for $24 \mathrm{~h}$. C-PARP1 and c-Caspase-3 were determined by Western blotting. (C) MGC803 cells were exposed to $25 \%$ and $100 \%$ of glucose for $48 \mathrm{~h}$ with $2.5 \mu \mathrm{g} / \mathrm{ml}$ cisplatin for $24 \mathrm{~h}$ and determined by Western blotting. (D) MGC803 cells were treated with $1 \mathrm{mM} 2$-DG for $48 \mathrm{~h}$ and $2.5 \mu \mathrm{g} / \mathrm{ml}$ cisplatin for $24 \mathrm{~h}$, then analyzed by Western blotting. (E) BGC823/DDP cells were treated with $2.5 \mathrm{mM} 2$-DG or $12.5 \%$ of glucose for $60 \mathrm{~h}$, during the last $36 \mathrm{~h}, 8 \mu \mathrm{g} / \mathrm{ml}$ DDP was added to the media. Cell apoptosis was analyzed by flow cytometry analysis. (F) MGC823 cells were treated with $1 \mathrm{mM} 2-\mathrm{DG}$ and $25 \%$ of glucose for $60 \mathrm{~h}$, during the last $36 \mathrm{~h}, 2.5 \mu \mathrm{g} / \mathrm{ml}$ DDP was added to the media. Cell apoptosis was determined by flow cytometry analysis. Results are from representative experiments in triplicate and shown as the mean \pm S.D. ${ }^{*} p<0.05$. 
A

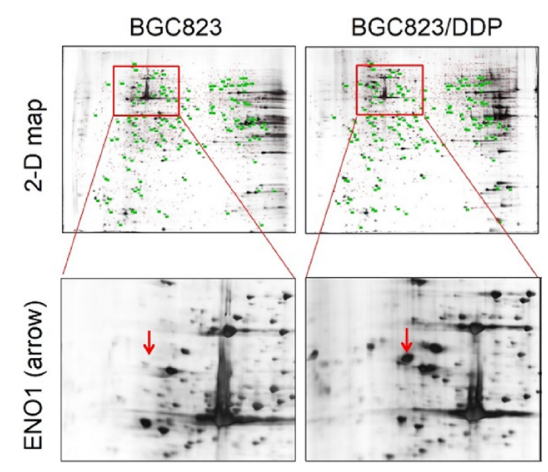

B

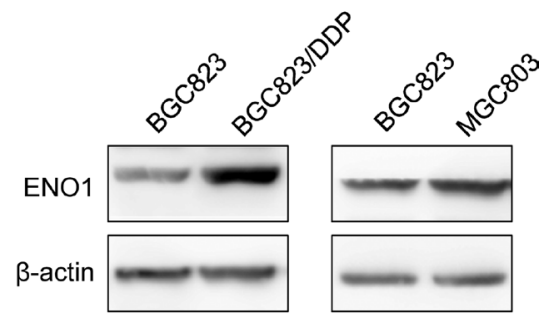

C

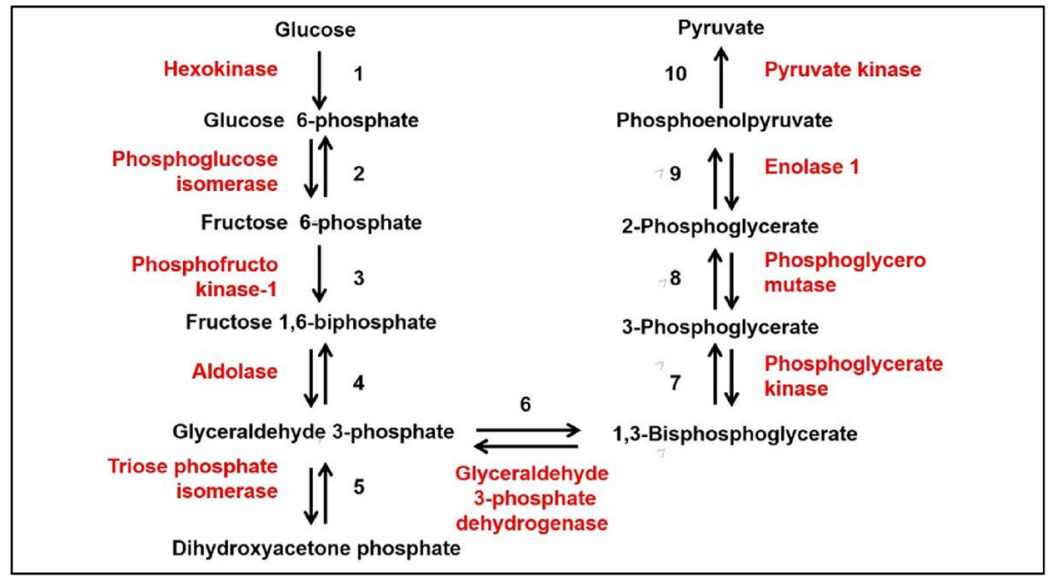

$\mathrm{D}$

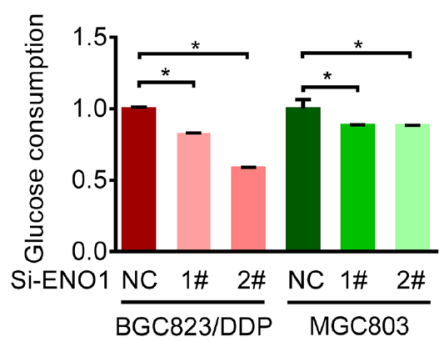

$\mathrm{F}$

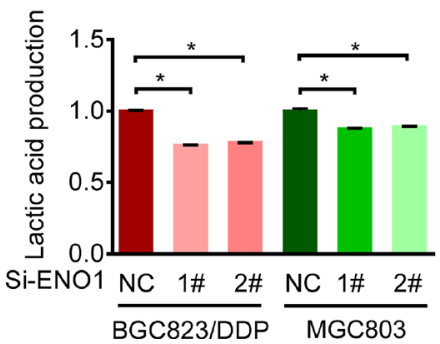

$E$

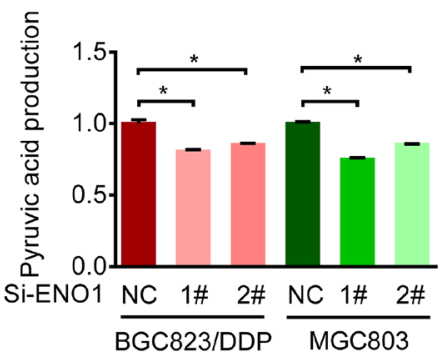

G

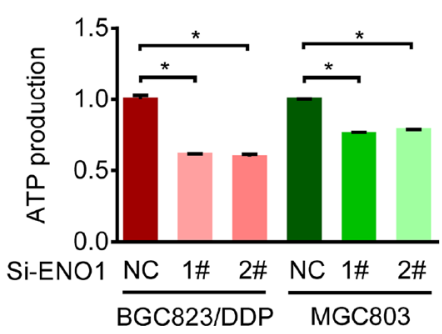

Figure 4: Cisplatin-resistant cells up-regulated ENO1 to enhance glycolysis. (A) The expressions of ENO1 were assessed by 2-DE-MS in BGC823 and BGC823/DDP cells. The red arrows showed the location of ENO1. (B) ENO1 expressions in BGC823, BGC823/ DDP and MGC803 cells were confirmed by Western blotting analysis. (C) The schematic flow chart showed 10 steps of glycolysis, and ENO1 catalyzed 2-phosphoglycerate (2-PG) to phosphoenolpyruvate (PEP). Enzymes are indicated by red font, two-way arrow means reversible reaction while one-way means irreversible. (D-G) BGC823/DDP and MGC803 cells were transiently transfected with con siRNA and ENO1 siRNA. After $36 \mathrm{~h}$, the culture media were replaced by fresh media. After another $36 \mathrm{~h}$, the supernatant were collected and the levels of glucose, pyruvic acid and lactic acid were measured according to the cell numbers, and another set of cell samples were lysed to estimate the levels of intracellular ATP. Results are from representative experiments in triplicate and shown as the mean \pm S.D. ${ }^{*} p<0.05$. 
A

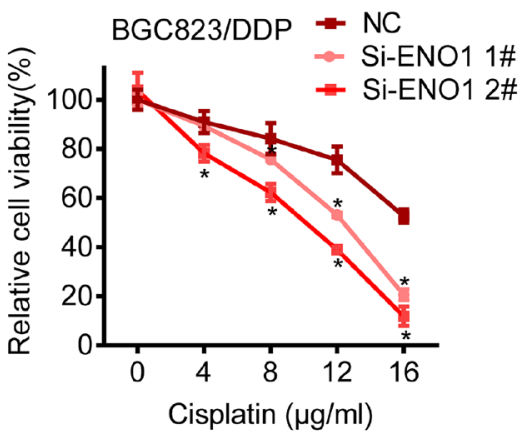

C

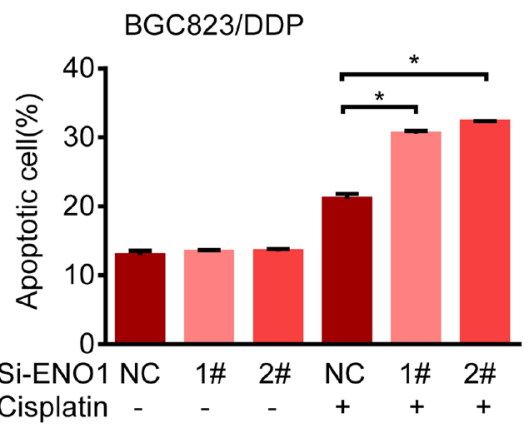

$E$

BGC823/DDP

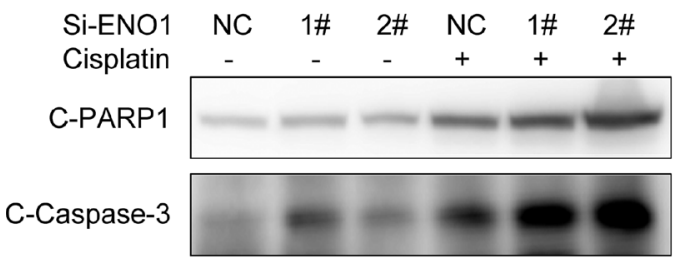

ENO1

$\beta$-actin
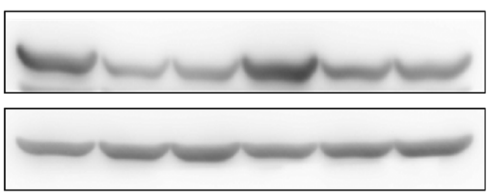

B

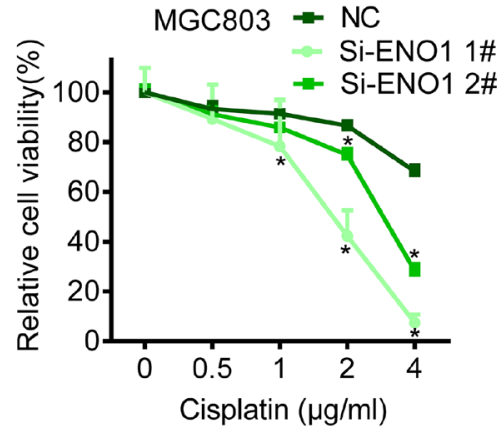

$\mathrm{D}$

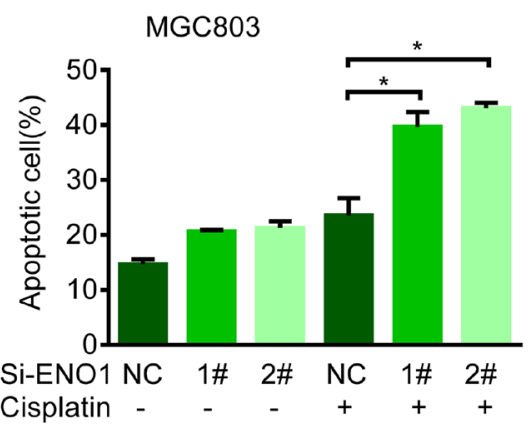

F

\section{MGC803}
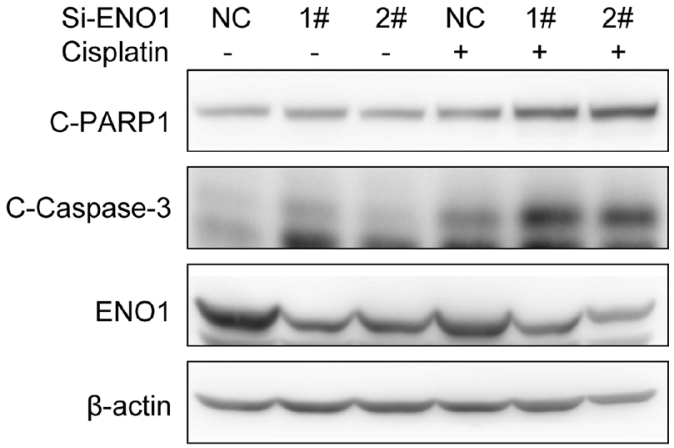

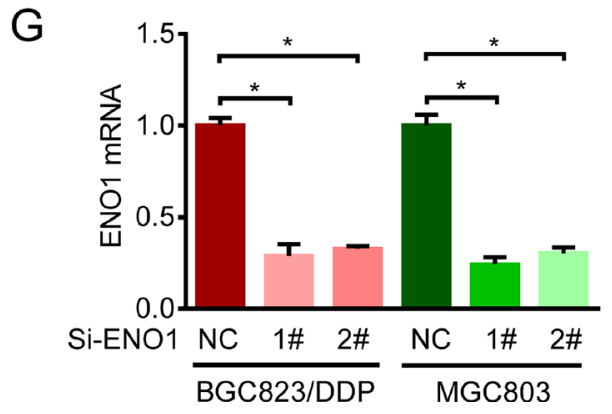

Figure 5: Knockdown ENO1 increased sensitivity to cisplatin. (A) BGC823/DDP cells were transfected with siRNA-ENO1 for $48 \mathrm{~h}$ and treated with different concentrations of cisplatin for another $24 \mathrm{~h}$. The cell viability was determined by MTS. (B) MGC803 cells were transfected with siRNA-ENO1 for $48 \mathrm{~h}$ and treated with different concentrations of cisplatin for another $24 \mathrm{~h}$. The cell viability was determined by MTS. (C-D) The apoptosis of BGC823/DDP and MGC803 transfected with siRNA-ENO1 in combination with cisplatin ( $8 \mu \mathrm{g} / \mathrm{ml}$ DDP for BGC823/DDP and $2.5 \mu \mathrm{g} / \mathrm{ml}$ DDP for MGC803) for $36 \mathrm{~h}$ were estimated with flow cytometry analysis. (E-F) BGC823/ DDP and MGC803 cells were transfected with siRNA-ENO1 for $48 \mathrm{~h}$ following cisplatin exposure for $24 \mathrm{~h}(8 \mu \mathrm{g} / \mathrm{ml}$ DDP for BGC823/ DDP and $2.5 \mu \mathrm{g} / \mathrm{ml}$ DDP for MGC803). C-PARP1, c-Caspase-3 and ENO1 were determined by Western blotting. (G) The knockdown efficiency was shown by QPCR after $72 \mathrm{~h}$ transfection. Results are from representative experiments in triplicate and shown as the mean \pm S.D. ${ }^{*} p<0.05$. 
and glycolysis enhancement in drug-resistant gastric cancer cells.

\section{ENO1 predicted a poor clinical outcome in gastric cancer}

We next explored the clinical relevance of ENO1 in gastric cancer patients. ENO1 expression in primary gastric adenocarcinoma and non-tumor tissues were evaluated by immunohistochemistry staining. As shown in Figure 8A and 8B, ENO1 expression was increased in tumor tissues (high expression rate: $13 \%$ in non-tumor tissues and $69 \%$ in tumor tissues). The association of ENO1 expression levels with various clinicopathologic characteristics in gastric cancer patients was summarized in Table 1. Interestingly, ENO1 protein was highly expressed in male patients (high expression rate: $85 \%$ in male and $58 \%$ in female, Chi-square test, $p<0.05$ ).
But its expression levels were not significantly associated with TNM stage and differentiation (Chi-square test, $p>0.05)$. Moreover, high expression of ENO1 had a strong association with shorter overall survival (OS) (Low ENO1 expression: 2532 days, 95\% CI: 1861-3203; High ENO1 expression: 1931 days, 95\% CI: 1406-2457, LogRank test, $p<0.05$, Figure $8 \mathrm{C}$ ). Univariate Cox regression analysis revealed that high ENO1 expression significantly increased two folds of death hazard ( $p<0.05$, Table 2 ). When other potential prognosis factors such as TNM stage, differentiation and gender were incorporated in the multivariate Cox regression, high ENO1 expression also displayed the trend to indicate shorter survival ( $p=0.07$, Figure 8D and Table 2). In contrast, ENO1 expression had no influence on progression free survival (PFS) (Low ENO1 expression: 788 days, 95\% CI: 520-1056; High ENO1 expression: 780 days, 95\% CI: 318-1242, LogRank test, $p>0.05$ and Table 3 ).

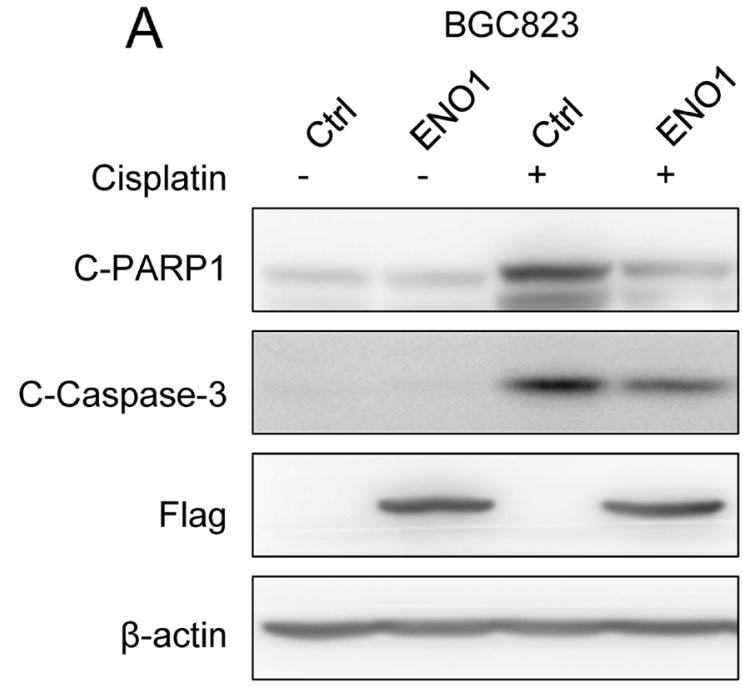

C
B
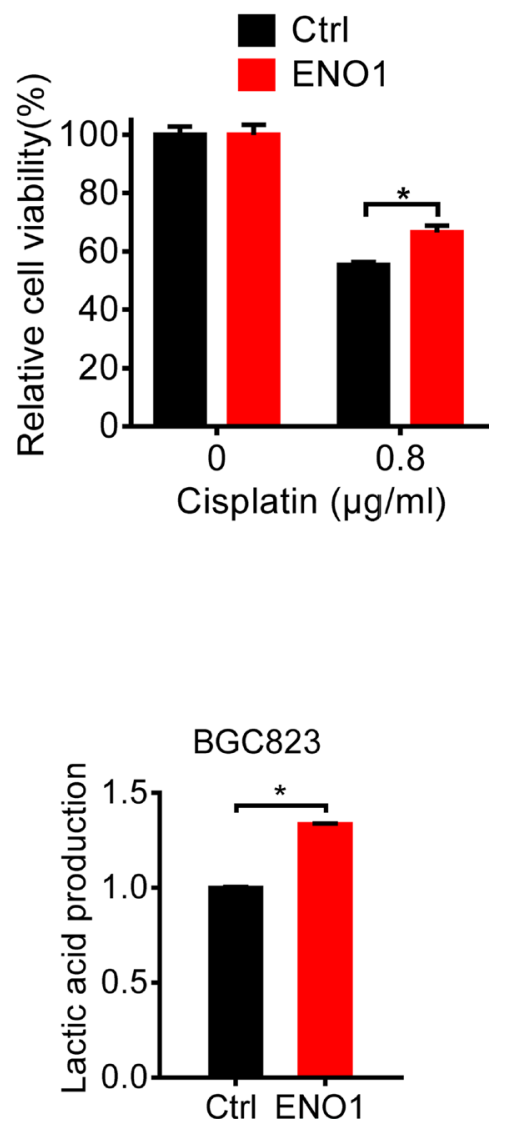

Figure 6: Overexpression of ENO1 in cisplatin-sensitive cells induced cisplatin-resistance by glycolysis promotion. (A) BGC823 cells were transfected with Flag-ENO1 plasmids for $48 \mathrm{~h}$ following $0.8 \mu \mathrm{g} / \mathrm{ml}$ cisplatin exposure for $24 \mathrm{~h}$. C-PARP1, c-Caspase-3, Flag-ENO1 and $\beta$-actin were assessed by Western blotting. (B) BGC823 cells were transfected with Flag-ENO1 for 48 h and treated with $0.8 \mu \mathrm{g} / \mathrm{ml}$ cisplatin for another $24 \mathrm{~h}$. The cell viability was measured by MTS. (C) BGC823 cells were transiently transfected with ENO1 plasmids. After $36 \mathrm{~h}$, the culture media were replaced by fresh media. After another $36 \mathrm{~h}$, the supernatant were collected and the levels of glucose, pyruvic acid and lactic acid were measured according to the cell numbers. Results are from representative experiments in triplicate and shown as the mean \pm S.D. ${ }^{*} p<0.05$. 


\section{DISCUSSION}

As one of hallmarks of human cancer cells, elevated uptake of glucose and accelerated glycolytic rates were first observed by Germany Biochemist Dr. Otto Heinrich Warburg and later confirmed by many studies [7, 20, 21].

Anti-cancer treatments like radiation and chemotherapy can induce free radicals to kill cancer cells. Therefore, enhanced glycolysis may contribute to drug resistance by increasing reducing capacity [8-10, 19, 22]. In addition, the intracellular microenvironment affected by elevated glycolysis can turn to be lower glucose concentration with high levels of lactate, pyruvate and ATP, thus facilitating the development of multiple drug resistance (MDR) [23-25]. The low glucose concentration in microenvironment increases the expression of glucose transporters and activates PI3K/AKT/mTOR to inhibit apoptosis and facilitate cellular survival [3,26]. Elevated lactate levels can reinforce DNA repair and promote cisplatin resistance in cervical carcinoma cells via the inactivation of histone deacetylase [27]. In addition, pyruvate can promote chemoresistance by up-regulating the expression of p-glycoprotein to enhance the efflux of chemotherapeutic drugs [28]. ATP was considered as a pivotal determinant in maintaining MDR phenotype partially because elevated ATP levels directly activated transporters with ATP-binding cassettes to exclude intracellular cytotoxic drugs [29]. As a result, depletion of ATP could eventually reverse chemoresistance [4, 8].

In this study, we found enhanced glycolysis in both intrinsic and acquired cisplatin-resistant gastric cancer cells. Both glucose consumption and lactate
A

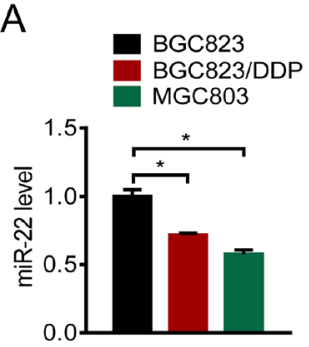

B

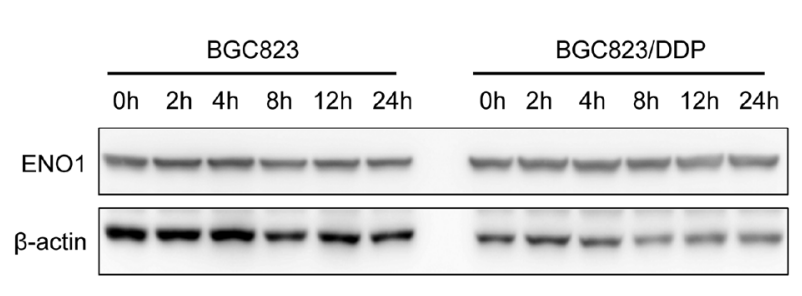

E

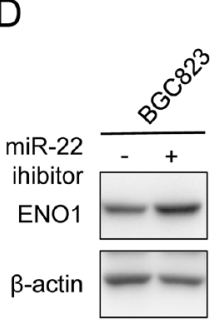

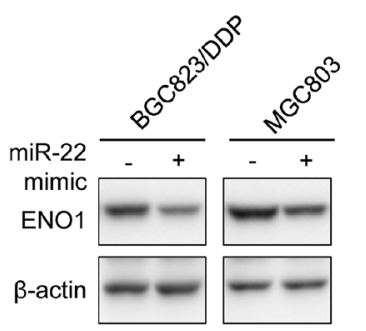

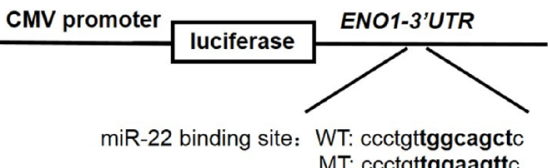

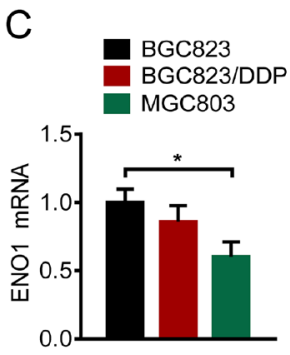

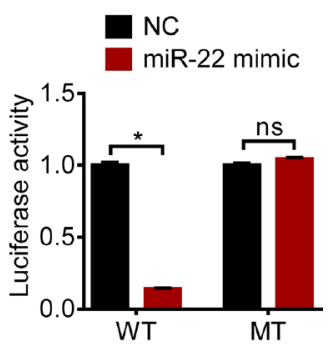

F

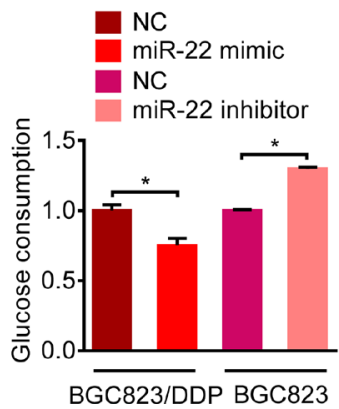

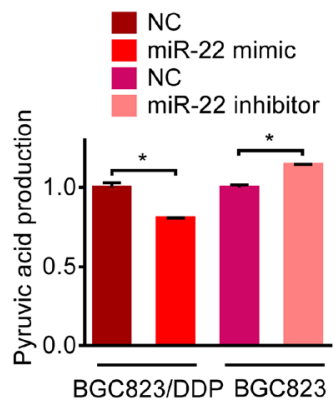

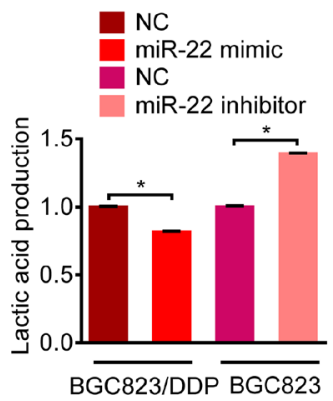

Figure 7: microRNA-22 targeted ENO1 mRNA. (A) ENO1 mRNA of BGC823, BGC823/DDP and MGC803 cells were evaluated by QPCR. (B) BGC823 and BGC823/DDP cells were treated with $50 \mu \mathrm{g} / \mathrm{ml}$ cycloheximide (CHX) to block new protein synthesis for $0 \mathrm{~h}$, $2 \mathrm{~h}, 4 \mathrm{~h}, 8 \mathrm{~h}, 12 \mathrm{~h}$ and $24 \mathrm{~h}$. ENO1 was determined by Western blotting. (C) QPCR was used to detect miRNA-22 in untreated BGC823, BGC823/DDP and MGC803 cells. (D) miRNA-22 mimic and inhibitor were transfected into certain cells for $72 \mathrm{~h}$, and ENO1 protein were tested by western blot. (E) The wild type and the mutant luciferase plasmids, all of which contained 3'-UTR segment of ENO1 were transfected into BGC823/DDP cells combined with miR-22 mimic for $48 \mathrm{~h}$, and luciferase activities were tested. (F) BGC823 cells and BGC823/DDP cells were transiently transfected with miR-22 inhibitor or mimic respectively. After $36 \mathrm{~h}$, the culture media were replaced by fresh media. After another $36 \mathrm{~h}$, the supernatant were collected and the levels of glucose, pyruvic acid and lactic acid were measured according to the cell numbers. Results are from representative experiments in triplicate and shown as the mean \pm S.D. ${ }^{*} p<0.05$; ns means no statistical significance $(p>0.05)$. 
production were increased in gastric cancer cells resistant to the well-used chemotherapeutic drug. Inhibition of glycolysis not only inhibited cell proliferation but also reversed resistance to cisplatin. Therefore, gastric cancer cells with drug resistance also developed dependence on enhanced glycolysis for cellular survival. There are many mechanisms proposed to contribute to the Warburg effect. For example, aberrant activation of oncogenic signaling pathways including Ras/MAPK, PI3K/AKT/ mTOR or loss of function of cancer suppressor genes like p53 which could promote the expression of glucose transporters and glycolytic enzymes [30-32]. Meanwhile, the metabolic products such as lactate can in turn promote glycolysis as a positive feedback [33]. Here, we identified another rate-limiting enzyme overexpression in both acquired and intrinsic drug-resistant gastric cancer cells by proteomic screening. ENO1 protein, which catalyzes 2-phosphoglycerate to phosphoenolpyruvate, was significantly overexpressed in BGC823/DDP and MGC803 cells.
In mammals, enolase has three isoforms, that is alpha-enolase, beta-enolase and gamma-enolase, encoded by three distinct genes [34]. Alpha-enolase (ENO1) is an essential glycolytic enzyme detected in nearly all adult human tissues. It has been reported that ENO1 was upregulated in various human cancers including gastric cancer [35, 36], glioma [37], breast cancer [38], lung cancer [39], head and neck cancer [40], endometrial carcinoma [41], pancreatic adenocarcinoma [42, 43], and Non-Hodgkin's Lymphomas (NHLs) [44]. Our results further confirmed these findings. ENO1 protein was highly expressed in tumor tissues in comparison with adjacent non-tumor tissues including gastric tissues with dysplasia (Figure 8 and data not shown). Interestingly, we also found that ENO1 expression was further increased in both acquired and intrinsic drug resistance. Depletion of ENO1 inhibited glycolysis and reversed drug resistance.

So far, glycolytic enzymes also have been reported in promoting drug resistance by other mechanisms in addition of activating metabolic flux [45-48]. For instance,
A

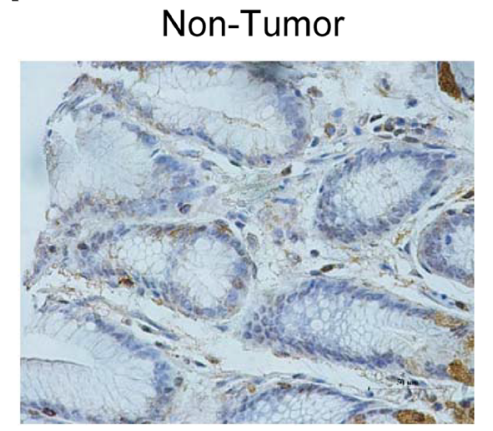

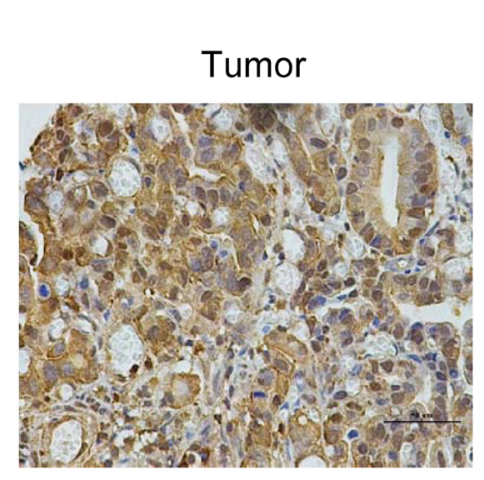
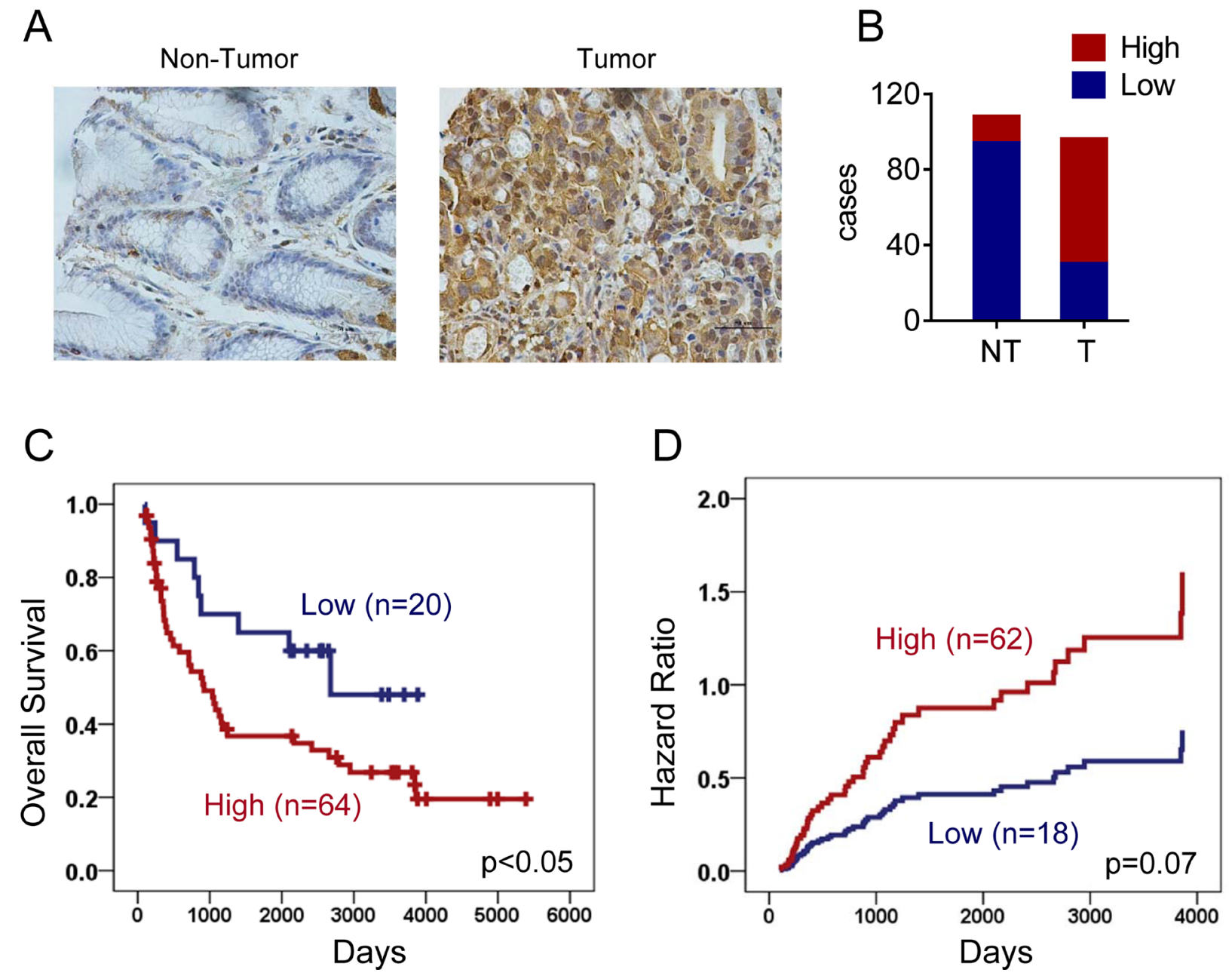

Figure 8: ENO1 predicted a poor clinical outcome in gastric cancer. (A) Expressions of ENO1 in normal and tumor gastric tissues were determined by immunohistochemistry staining. (B) Statistical results showed patients of gastric cancer expressed high level of ENO1. (C) Overexpression of ENO1 protein predicted shorter overall survival (OS) of gastric cancer patients $(p<0.05)$. (D) Multivariate Cox regression indicated high ENO1 expression associated with shorter survival. 
Table 1: ENO1 expression in gastric cancer

\begin{tabular}{lccc}
\hline Variable & Low expression & High expression & $p$-value \\
\hline Gender & 17 & 37 & 0.045 \\
F & 8 & 45 & \\
M & & & \\
TNM & 7 & 11 & 0.109 \\
I & 9 & 23 & \\
II & 5 & 35 & \\
III & 2 & 11 & 0.877 \\
IV & & & \\
Differentiation & 15 & 50 & \\
Low & 10 & 31 & \\
Moderate or High &
\end{tabular}

Table 2: Cox regression analysis of overall survival in gastric cancer

\begin{tabular}{|c|c|c|c|c|}
\hline \multirow{2}{*}{ Variable } & \multicolumn{2}{|c|}{ Univariate } & \multicolumn{2}{|c|}{ Multivariate } \\
\hline & RR $(95 \%$ CI $)$ & $p$-value & RR (95\% CI) & $p$-value \\
\hline \multicolumn{5}{|l|}{ Gender } \\
\hline Female & 1.00 & \multirow{2}{*}{0.946} & 1.00 & \multirow{2}{*}{0.986} \\
\hline Male & $1.0(0.6-1.6)$ & & $1.0(0.6-1.8)$ & \\
\hline \multicolumn{5}{|l|}{ Differentiation } \\
\hline Moderate or High & 1.00 & \multirow{2}{*}{0.322} & 1.00 & \multirow{2}{*}{0.657} \\
\hline Low & $1.3(0.8-2.1)$ & & $1.2(0.6-2.2)$ & \\
\hline \multicolumn{5}{|l|}{ TNM Stage } \\
\hline I & 1.00 & \multirow{4}{*}{$<0.01$} & 1.00 & \multirow{4}{*}{$<0.01$} \\
\hline II & $5.7(2.0-16.5)$ & & $4.8(1.4-17.0)$ & \\
\hline III & $5.4(2.0-15.2)$ & & $5.0(1.4-17.2)$ & \\
\hline IV & $10.4(3.3-32.2)$ & & $10.4(2.7-39.4)$ & \\
\hline \multicolumn{5}{|l|}{ ENO1 expression } \\
\hline Low & 1.00 & \multirow{2}{*}{$<0.05$} & 1.00 & \multirow{2}{*}{0.07} \\
\hline High & $2.1(1.0-4.3)$ & & $2.1(0.9-2.2)$ & \\
\hline
\end{tabular}

hexokinase (HK), one of the rate-limiting enzymes in glycolysis, can locate to mitochondrial outer membrane and inhibit mitochondria-dependent apoptosis [49, 50]. Similarly, ENO1 can also locate in nucleus to inhibit the transcription of c-myc, a proto-oncogene, which acts as a negative transcription factor [51]. However, we failed to detect the enhanced nuclear location of ENO1 in either BGC823/DDP or MGC803 cells (date not shown). Therefore, the stimulation of drug resistance by increased ENO1 expression in gastric cancer was most likely attributed to its enzyme activity to regulate glycolysis rather than its function as a transcription regulator. Inhibition of glycolysis by ENO1 depletion reduced glucose consumption, and the production of lactate, pyruvate and ATP, thus reversing drug resistance. How inhibition of glycolysis reversed drug resistance remains to be clarified. However, it has been reported that inhibition of ENO1 could induce autophagy to arrest cellular growth [52]. In addition, many metabolites including pyruvate were able to reprogram gene expression in an epigenetic manner [53]. Therefore, the understanding of differential gene expression before and after ENO1 depletion by high throughput methods would be valuable to understand the regulation of drug resistance by glycolysis.

Studies have revealed that high level of ENO1 was strongly linked to poor prognosis of cancer patients 
Table 3: Cox regression analysis of progression free survival in gastric cancer

\begin{tabular}{|c|c|c|c|c|}
\hline \multirow{2}{*}{ Variable } & \multicolumn{2}{|c|}{ Univariate } & \multicolumn{2}{|c|}{ Multivariate } \\
\hline & RR $(95 \%$ CI $)$ & $p$-value & RR (95\% CI) & $p$-value \\
\hline \multicolumn{5}{|l|}{ Gender } \\
\hline Female & 1.00 & \multirow{2}{*}{0.557} & 1.00 & \multirow{2}{*}{0.452} \\
\hline Male & $0.9(0.5-1.4)$ & & $0.8(0.4-1.5)$ & \\
\hline \multicolumn{5}{|l|}{ Differentiation } \\
\hline Moderate or High & 1.00 & \multirow{2}{*}{0.105} & 1.00 & \multirow{2}{*}{0.320} \\
\hline Low & $1.5(0.9-2.6)$ & & $1.4(0.7-2.9)$ & \\
\hline \multicolumn{5}{|l|}{ TNM Stage } \\
\hline I & 1.00 & \multirow{4}{*}{$<0.01$} & 1.00 & \multirow{4}{*}{$<0.01$} \\
\hline II & $4.7(1.8-12.4)$ & & $3.5(1.1-11.5)$ & \\
\hline III & $5.2(2.0-13.5)$ & & $4.4(1.4-13.7)$ & \\
\hline IV & $12.8(4.4-37.1)$ & & $9.8(2.9-33.4)$ & \\
\hline \multicolumn{5}{|l|}{ ENO1 expression } \\
\hline Low & 1.00 & \multirow{2}{*}{0.884} & 1.00 & \multirow{2}{*}{0.912} \\
\hline High & $0.9(0.5-1.9)$ & & $1.1(0.5-2.3)$ & \\
\hline
\end{tabular}

$[35,37,38,44]$. Consistently, we indeed found that high ENO1 expression predicted shorter overall survival of gastric cancers. Therefore, ENO1 was proposed to be a potential tumor biomarker of chemoresistance and overall prognosis [39, 41, 43]. Certainly, its clinical value warrants further validations with a larger cohort.

The increased expression of ENO1 in some cancers was resulted from high mRNA levels. Actually, ENO1 is a direct transcriptional target of HIF- $1 \alpha[19,54,55]$. However, to our surprise, mRNA of ENO1 were even slightly decreased in MGC803 and BGC823/DDP cells. Interestingly, high level of ENO1 protein with low ENO1 mRNA level was also detected in methotrexateresistant breast cancer cells [56]. We indeed found that the discrepancy between protein and mRNA of ENO1 was attributed to the downregulation of ENO1-tagreting miR-22, but not the post-translational regulation of its protein stability. Interestingly, miR-22 played different roles in tumorigenesis depending on caner types [57-60]. However, miR-22 seemed to serve as a novel tumor suppressor in gastric cancers. MiR-22 expression was significantly reduced in gastric cancer tissues when compared with normal adjacent mucosa, and the reduced expression of miR-22 indicated shorter overall survival for patients [61]. Overexpression of miR-22 could inhibit gastric cancer growth [62-64]. These data were consistent with our findings, and we further discovered that low expression of miR-22 promoted glycolysis and cisplatin-resistance by up-regulating ENO1. It remains unclear how miR-22 expression was reduced in gastric cancers. Interestingly, STAT5 could downregulate miR-22 expression by binding the promoter of its host gene. Inhibition of Jak3, STAT3 and STAT5 triggered overexpression of miR-22 and suppressed cancer proliferation in cutaneous T-Cell lymphoma [65]. Therefore, miR-22 could be valuable to target ENO1 to overcome drug resistance in gastric cancers.

In conclusion, gastric cancers could develop a cisplatin-resistant phenotype by glycolysis acceleration and dependence. Glucose deprivation or glycolysis inhibition can sensitize cells to chemotherapy. ENO1 serves as a master regulator of tumor glycolysis and predicts an unfavorable prognosis for gastric cancers. MiR-22 targets 3'-UTR of ENO1 to repress its expression and reduced expression of miR-22 eventually promote ENO1 expression to enhance glycolysis and drug resistance. Therefore, inhibition of ENO1 or up-regulation of miR-22 could restrain glycolysis to increase cisplatin sensitivity.

\section{MATERIALS AND METHODS}

\section{Cells, antibodies, chemicals, culture medium and plasmids}

Human gastric cancer cell lines BGC823 and MGC803 were obtained from the Type Culture Collection of the Chinese Academy of Sciences (Shanghai, China). The culture media used were RPMI 1640 containing $10 \%$ of fetal bovine serum, $100 \mathrm{U} / \mathrm{ml}$ of penicillin and $100 \mu \mathrm{g} / \mathrm{ml}$ of streptomycin (Invitrogen, Carsbad, CA, USA). The cells were grown in a humidified incubator $\left(37^{\circ} \mathrm{C}, 5 \% \mathrm{CO}_{2}\right)$. The conditional glucose media were mixed by RPMI 1640 complete medium (11 mM glucose) and RPMI 1640 glucose-free medium (Gibico, Grand Island, NY, USA) according to proportions of $0 \%, 12.5 \%$, 
Table 4: Sequences of oligos used in the study

\begin{tabular}{ll}
\hline Name & Sequence \\
\hline h-ENO1-RT-PCR & F:TGAGGGAATGAGTGACGGC \\
h- $\beta$-Actin-RT-PCR & R:ACAGCCTTTGAGACACCCTTC \\
& F:GCTATCCCTGTACGCCTCTG \\
hsa-miR-22-3p & R:AGGAAGGAAGGCTGGAAGAG \\
ENO1-3' UTR-F & AAGCTGCCAGTTGAAGAACTGT \\
ENO1-3' UTR-R & GGAGAGCTCGCTGTGGGCAGGCAAGC \\
ENO1-3' UTR-mutant-F & GCGAAGCTTCTCATGGGTCACTGAGGCTTTTT \\
ENO1-3' UTR-mutant-R & CTCCCTGGAGCCCTGTTGGAAGTTCTAGCTTTGCA \\
ENO1 siRNA 1\# & TGCAAAGCTAGAACTTCCAACAGGGCTCCAGGGAG \\
ENO1 siRNA 2\# & 5'-GGAGAAAUAUGGGAAAGAUTT-3' \\
hsa-miR-22-3p mimic & 5'-CCCAGUGGUGUCUAUCGAATT-3' \\
hsa-miR-22-3p inhibitor & AAGCUGCCAGUUGAAGAACUGU \\
\hline
\end{tabular}

$25 \%$ and $100 \%$ at a certain ratio, containing dialyzed fetal bovine serum (Gibico, Grand Island, NY, USA, NZ origin). Cisplatin was obtained from Sigma-Aldrich (St. Louis, MO, USA) and stored at room temperature in darkness. The cisplatin-resistant BGC823/DDP cells were derived from the parental BGC823 cells as previously described [16]. In short, BGC823 cells were persistently exposed to increasing concentration gradient of cisplatin from $0.05 \mu \mathrm{g} / \mathrm{ml}$ to $1 \mu \mathrm{g} / \mathrm{ml}$. Before each experiment, BGC823/DDP cells were grown in cisplatin-free RPMI 1640 media for 2 weeks. Antibody for ENO1 was bought from Proteintech (Rosemont, PA, USA). Antibodies for $\beta$-actin, cleaved Caspase-3 and cleaved PARP1 were from Cell Signaling Technology (Boston, MA, USA). Antibody for Flag was from Sigma (St.Louis, MO, USA). 2-DG, CHX, MTS and other chemicals were all bought from Sigma-Aldrich (St. Louis, MO, USA). The human ENO1 ORF mammalian expression plasmid was constructed on the vector pCMV3-N-FLAG and purchased from Sino Biological Inc (Beijing, China, Catalog Number: HG11554-NF).

The pMIR-Luciferase-REPORT-ER vectors were obtained from Applied Biosystems (Foster City, CA, USA).

\section{SiRNA, miRNA mimics/inhibitors and plasmids transfection}

The ENO1 siRNAs were synthesized by Genepharma (Shanghai, China) for transient knockdown and listed in Table 4. Briefly, cells were seeded in 6-well plates overnight, and subsequently transfected with siRNA or miRNA mimics/inhibitors using lipofectamine RNAiMax (Invitrogen, Carsbad, CA, USA) and the plasmid DNA with X-GENE (Roche Diagnostics, Indianapolis, IN, USA) according to the manufacturer's instructions. The media were changed after $24 \mathrm{~h}$ transfection and the total time for transfection was $72 \mathrm{~h}$.

\section{RNA isolation, reverse transcription and quantitative PCR}

Total RNA was extracted by Trizol reagent (Invitrogen, Carsbad, CA, USA) and miRNA was extracted by MIRNeasy Mini Kit (QIAGEN Gmbh, Hilden, Germany) following the manufacturer's instructions. RNA concentrations were measured by absorbance (A260) on NanoDrop 1000 (Nanodrop, Wilmington, DE, USA). $1 \mu \mathrm{g}$ of total RNA was performed reverse transcription reaction with High Capacity cDNA Reverse Transcription kit (Applied Biosystems, Foster City, CA, USA, 4375222). The quantitative realtime PCR was conducted by using SYBR Green Master Mix (Applied Biosystems, Foster City, CA, USA) to determine mRNA levels while miScript PCR system (QIAGEN, Hilden, Germany) for microRNA expression analysis respectively. $\beta$-actin and U6 were used for the normalization of mRNA and microRNA respectively. The primers used in this study were listed in Table 4.

\section{Two-dimensional electrophoresis and mass spectrometry}

2-DE and mass spectrometry (MS) were performed as previously described [16]. Briefly, same amount of samples of BGC823 cells and BGC823/DDP cells were loaded on the 2-D gels, and then gels were stained with silver. The following criteria were used to identify differentially expressed proteins: spot intensity $\geq 2$-fold increase or decrease in BGC823/DDP cells in comparison with BGC823 cells. The proteins were analyzed by SwissProt and NCBI non-redundant databases. 


\section{Luciferase activity assay}

3'-UTR segment of the ENO1 with wild or mutant miR-22 binding sites were amplified by polymerase chain reaction (PCR) and inserted into the pGEM-T Easy vector (Promega Corporation, Madison, WI, USA) for sequence validation. The correct insert was again cloned into the pMIR-Luciferase-REPORTER vectors. The restriction enzymes were Sac I and Hind III. The primers used were shown in Table 4. The resultant plasmids were cotransfected with miR-22 mimics by using lipofectamine RNAiMax. After $48 \mathrm{~h}$ transfection, the luciferase activities were measured by the Dual-GLO Luciferase Assay System (Promega Corporation, Madison, WI, USA).

\section{Cell viability assay}

Cells viability was determined by Cell Titer $96{ }^{\circledR} \mathrm{AQueous}$ Cell Proliferation Assay kit (MTS assay) (Promega Corporation, Madison, WI, USA). $0.8 \times 10^{4}$ BGC823 cells and BGC823/DDP cells or $0.6 \times 10^{4}$ MGC803 cells were seeded per well in the 96-well plates. After $24 \mathrm{~h}$, cells were subjected to different concentrations of 2-DG $(0.5 \mathrm{mM}, 1 \mathrm{mM}, 2 \mathrm{mM}, 4 \mathrm{mM}$ and $8 \mathrm{mM})$ or glucose $(0 \%, 12.5 \%, 25 \%$ and $100 \%)$ for $48 \mathrm{~h}$ with or without DDP. The conditioned glucose media were mixed by RPMI 1640 complete medium (11 mM glucose) and RPMI 1640 glucose-free medium according to proportion of $0 \%, 12.5 \%, 25 \%$ and $100 \%$. BGC $823 / \mathrm{DDP}$ was treated with $4 \mu \mathrm{g} / \mathrm{ml}, 8 \mu \mathrm{g} / \mathrm{ml}, 12 \mu \mathrm{g} / \mathrm{ml}$ and $16 \mu \mathrm{g} / \mathrm{ml}$ DDP while MGC803 with $0.5 \mu \mathrm{g} / \mathrm{ml}, 1 \mu \mathrm{g} / \mathrm{ml}, 2 \mu \mathrm{g} / \mathrm{ml}$ and $4 \mu \mathrm{g} / \mathrm{ml}$ DDP respectively for $24 \mathrm{~h}$.

\section{Flow cytometry analysis}

$3 \times 10^{5}$ BGC823/DDP and $2 \times 10^{5}$ MGC803 cells were seeded in 6-well plates, and the next day changed for 2-DG (2.5 mM for BGC823/DDP and $1 \mathrm{mM}$ for MGC803) or hypoglycemic media $(12.5 \%$ glucose for BGC $823 / \mathrm{DDP}$ and $25 \%$ glucose for MGC803) for $60 \mathrm{~h}$, until the last $36 \mathrm{~h}, \mathrm{BGC} 823 / \mathrm{DDP}$ cells were added with $8 \mu \mathrm{g} / \mathrm{ml}$ DDP and MGC803 with $2.5 \mu \mathrm{g} / \mathrm{ml}$ DDP respectively. Apoptotic cell death was determined by using the FITC Annexin V Apoptosis Detection Kit I (BD Bioscience, Bedford, MA, USA) according to the manufacturer's instruction. Cells were washed twice with cold PBS and then suspended at a concentration of $1 \times 10^{6} \mathrm{cell} / \mathrm{s} / \mathrm{ml}$ in $1 \times$ Binding Buffer. Then $100 \mu \mathrm{l}$ cellular suspensions were added with $5 \mu \mathrm{l}$ of FITC Annexin V and $5 \mu \mathrm{PI}$, and then incubated for $15 \mathrm{~min}$ at room temperature in darkness before analyzed by flow cytometry.

\section{Western blotting}

Western blot analyses were performed as previously described [66]. Equal amounts of proteins were separated by SDS-PAGE and transferred to PVDF membrane. Interested proteins were probed with the indicated primary antibodies followed by incubation in HRP-conjugated corresponding secondary antibodies and revealed by enhanced chemiluminescence (Millipore, Billerica, MA, USA).

\section{Glucose consumption}

Cells were plated in the six-well plates, after $24 \mathrm{~h}$ the culture media were replaced by $3 \mathrm{ml}$ fresh media with different treatments. Then after certain period, the supernatant were collected and glucose concentrations were measured by Abbott ArchitectC16000 (Abbott Park, North Chicago, Illinois, USA). The cells left were trypsinized and counted for three times. The glucose consumption levels were standardized to $\mu \mathrm{mol} / 10^{6}$ cells. The fold changes were normalized by BGC 823 consumption.

\section{Lactic acid and pyruvic acid measurement}

The supernatant of cells were collected after treatment and lactic acid and pyruvic acid were measured by colorimetric method following the manufacturer's instructions of Lactic Acid assay kit and Pyruvate assay kit (Nanjing Jiancheng bioengneering institute, Nanjing, China). The cell numbers were counted for three times, and finally, the acid production were the measured by $\mu \mathrm{mol} / 10^{6}$ cells.

\section{Intracellular ATP measurement}

Briefly, cells were seeded for $24 \mathrm{~h}$ and then replaced by fresh media with different treatments. After cultivation, media were removed, cells lysates were measured using luciferase-based ATP Assay Kit (Beyotime, Shanghai, China) by following the assay instructions for intracellular ATP levels. The unit of measurement was nmol $/ 10^{6}$ cells.

\section{Immunohistochemical staining}

The paraffin sections were prepared from gastric tissue biochips, containing normal, precancerosis and tumors. The indirect streptavidinperoxidase method was used for detecting protein ENO1 expression level according to manufacturer's introduction. The antibody was rabbit anti-ENO1 antibody (1:1000, Proteintech, Rosemont, PA, USA). The stained specimens were evaluated separately by two pathologists. The scores were based on expression intensity and its proportion, and finally divided into four groups, none (0), weak (1), medium (2) and strong (3). Score 0-1 was defined as low expression while Score 2-3 as high.

\section{Statistical analysis}

All values were expressed as the mean \pm S.D. The statistical significance of the differences between groups 
was determined by the parametric unpaired Student's $t$-test. Statistical significance was accepted if $p<0.05$.

\section{Abbreviations}

ATP, adenosine triphosphate; caspase-3, cysteineaspartic acid protease-3; CHX, cycloheximide; DDP, cis-diammine dichloride-platinum(II); ENO1, Enolase 1; GSH, glutathione; Glu, Glucose; MDR, multiple drug resistance; miRNA, microRNA; MS, mass spectrometry; MT, mutant; NADPH, nicotinamide adenine dinucleotide phosphate; OS, overall survival; OXPHOS, oxidative phosphorylation; PARP1, poly(ADP-ribose) polymerase 1; PCR, polymerase chain reaction; PFS, progression free survival; PI, phosphatidylinositol; ROS, reactive oxygen species; RT-PCR, reverse transcription polymerase chain reaction; 2-DE, two-dimensional electrophoresis; 2-DG, 2-Deoxy-D-glucose.

\section{ACKNOWLEDGMENTS AND FUNDING}

This study was supported in part by the National Natural Science Foundation of China (grant number 81502609), and the National Natural Science Foundation of Zhejiang province (grant number LQ15H160004), the Department of Health in Zhejiang Province (grant number 2016143571; WKJ-ZJ-1520) and Zhejiang Provincial Program High-level Innovative Health talents.

\section{CONFLICTS OF INTEREST}

The authors declare no conflicts of interest.

\section{REFERENCES}

1. Shen L, Shan YS, Hu HM, Price TJ, Sirohi B, Yeh KH, Yang YH, Sano T, Yang HK, Zhang X, Park SR, Fujii M, Kang YK, et al. Management of gastric cancer in Asia: resource-stratified guidelines. Lancet Oncol. 2013; 14: e535-47. doi: 10.1016/S1470-2045(13)70436-4.

2. Myint K, Li Y, Paxton J, McKeage M. Multidrug ResistanceAssociated Protein 2 (MRP2) Mediated Transport of Oxaliplatin-Derived Platinum in Membrane Vesicles. PLoS One. 2015; 10:e0130727. doi: 10.1371/journal. pone.0130727.

3. Bhattacharya B, Low SH, Soh C, Kamal Mustapa N, Beloueche-Babari M, Koh KX, Loh J, Soong R. Increased drug resistance is associated with reduced glucose levels and an enhanced glycolysis phenotype. Br J Pharmacol. 2014; 171:3255-67. doi: 10.1111/bph.12668.

4. Zheng X, Andruska N, Lambrecht MJ, He S, Parissenti A, Hergenrother PJ, Nelson ER, Shapiro DJ. Targeting multidrug-resistant ovarian cancer through estrogen receptor alpha dependent ATP depletion caused by hyperactivation of the unfolded protein response. Oncotarget. 2016 Jul 24. doi: 10.18632/oncotarget.10819. [Epub ahead of print].

5. Fanciulli M, Bruno T, Giovannelli A, Gentile FP, Di Padova M, Rubiu O, Floridi A. Energy metabolism of human LoVo colon carcinoma cells: correlation to drug resistance and influence of lonidamine. Clin Cancer Res. 2000; 6:1590-7.

6. Xu RH, Pelicano H, Zhou Y, Carew JS, Feng L, Bhalla KN, Keating MJ, Huang P. Inhibition of glycolysis in cancer cells: a novel strategy to overcome drug resistance associated with mitochondrial respiratory defect and hypoxia. Cancer Res. 2005; 65:613-21.

7. Hanahan D, Weinberg RA. Hallmarks of cancer: the next generation. Cell. 2011; 144:646-74. doi: 10.1016/j. cell.2011.02.013.

8. Bean JF, Qiu YY, Yu S, Clark S, Chu F, Madonna MB. Glycolysis inhibition and its effect in doxorubicin resistance in neuroblastoma. J Pediatr Surg. 2014; 49:981-4. doi: 10.1016/j.jpedsurg.2014.01.037.

9. De Rosa V, Iommelli F, Monti M, Fonti R, Votta G, Stoppelli MP, Del Vecchio S. Reversal of Warburg Effect and Reactivation of Oxidative Phosphorylation by Differential Inhibition of EGFR Signaling Pathways in Non-Small Cell Lung Cancer. Clin Cancer Res. 2015; 21: 5110-20. doi: 10.1158/1078-0432.CCR-15-0375.

10. Ma S, Jia R, Li D, Shen B. Targeting Cellular Metabolism Chemosensitizes the Doxorubicin-Resistant Human Breast Adenocarcinoma Cells. Biomed Res Int. 2015; 2015: 453986. doi: 10.1155/2015/453986.

11. Lu CW, Lin SC, Chen KF, Lai YY, Tsai SJ. Induction of pyruvate dehydrogenase kinase-3 by hypoxia-inducible factor-1 promotes metabolic switch and drug resistance. J Biol Chem. 2008; 283:28106-14. doi: 10.1074/jbc. M803508200.

12. Locasale JW, Cantley LC. Altered metabolism in cancer. BMC Biol. 2010; 8:88. doi: 10.1186/1741-7007-8-88.

13. Lu J, Tan M, Cai Q. The Warburg effect in tumor progression: mitochondrial oxidative metabolism as an antimetastasis mechanism. Cancer Lett. 2015; 356:156-64. doi: 10.1016/j.canlet.2014.04.001.

14. Stowe DF, Camara AK. Mitochondrial reactive oxygen species production in excitable cells: modulators of mitochondrial and cell function. Antioxid Redox Signal. 2009; 11:1373-414. doi: 10.1089/ARS.2008.2331.

15. Kamarajugadda S, Stemboroski L, Cai Q, Simpson NE, Nayak S, Tan M, Lu J. Glucose oxidation modulates anoikis and tumor metastasis. Mol Cell Biol. 2012; 32:1893-907. doi: 10.1128/MCB.06248-11.

16. Xu W, Wang S, Chen Q, Zhang Y, Ni P, Wu X, Zhang J, Qiang F, Li A, Roe OD, Xu S, Wang M, Zhang R, et al. TXNL1-XRCC1 pathway regulates cisplatin-induced cell death and contributes to resistance in human gastric cancer. Cell Death Dis. 2014; 5:e1055. doi: 10.1038/cddis.2014.27. 
17. Zhou Y, Tozzi F, Chen J, Fan F, Xia L, Wang J, Gao G, Zhang A, Xia X, Brasher H, Widger W, Ellis LM, Weihua Z. Intracellular ATP levels are a pivotal determinant of chemoresistance in colon cancer cells. Cancer Res. 2012; 72:304-14. doi: 10.1158/0008-5472.CAN-11-1674.

18. Qian Y, Wang X, Liu Y, Li Y, Colvin RA, Tong L, $\mathrm{Wu}$ S, Chen X. Extracellular ATP is internalized by macropinocytosis and induces intracellular ATP increase and drug resistance in cancer cells. Cancer Lett. 2014; 351: 242-51. doi: 10.1016/j.canlet.2014.06.008.

19. Woo YM, Shin Y, Lee EJ, Lee S, Jeong SH, Kong HK, Park EY, Kim HK, Han J, Chang M, Park JH. Inhibition of Aerobic Glycolysis Represses Akt/mTOR/HIF-1alpha Axis and Restores Tamoxifen Sensitivity in AntiestrogenResistant Breast Cancer Cells. PLoS One. 2015; 10:e132285. doi: 10.1371/journal.pone.0132285.

20. Hirayama A, Kami K, Sugimoto M, Sugawara M, Toki N, Onozuka H, Kinoshita T, Saito N, Ochiai A, Tomita M, Esumi H, Soga T. Quantitative metabolome profiling of colon and stomach cancer microenvironment by capillary electrophoresis time-of-flight mass spectrometry. Cancer Res. 2009; 69:4918-25. doi: 10.1158/0008-5472.CAN-08-4806.

21. Warburg O, Wind F, Negelein E. The Metabolism of Tumors in the Body. J Gen Physiol. 1927; 8:519-30.

22. Milane L, Ganesh S, Shah S, Duan ZF, Amiji M. Multimodal strategies for overcoming tumor drug resistance: hypoxia, the Warburg effect, stem cells, and multifunctional nanotechnology. J Control Release. 2011; 155:237-47. doi: 10.1016/j.jconrel.2011.03.032.

23. Griguer CE, Oliva CR. Bioenergetics pathways and therapeutic resistance in gliomas: emerging role of mitochondria. Curr Pharm Des. 2011; 17:2421-7.

24. Mentis AF, Kararizou E. Metabolism and cancer: an upto-date review of a mutual connection. Asian Pac J Cancer Prev. 2010; 11: 1437-44.

25. Suh DH, Kim MK, No JH, Chung HH, Song YS. Metabolic approaches to overcoming chemoresistance in ovarian cancer. Ann N Y Acad Sci. 2011; 1229:53-60. doi: 10.1111/j.1749-6632.2011.06095.x.

26. Altman BJ, Rathmell JC. Metabolic stress in autophagy and cell death pathways. Cold Spring Harb Perspect Biol. 2012; 4: a008763. doi: 10.1101/cshperspect.a008763.

27. Wagner W, Ciszewski WM, Kania KD. L- and D-lactate enhance DNA repair and modulate the resistance of cervical carcinoma cells to anticancer drugs via histone deacetylase inhibition and hydroxycarboxylic acid receptor 1 activation. Cell Commun Signal. 2015; 13:36. doi: 10.1186/s12964015-0114-x.

28. Wartenberg $M$, Richter $M$, Datchev A, Gunther S, Milosevic N, Bekhite MM, Figulla HR, Aran JM, Petriz J, Sauer H. Glycolytic pyruvate regulates P-Glycoprotein expression in multicellular tumor spheroids via modulation of the intracellular redox state. J Cell Biochem. 2010; 109: 434-46. doi: 10.1002/jcb.22422.
29. Ruetz S, Gros P. A mechanism for P-glycoprotein action in multidrug resistance: are we there yet? Trends Pharmacol Sci. 1994; 15:260-3.

30. Boguski MS, Lowe TM, Tolstoshev CM. dbEST - database for "expressed sequence tags". Nat Genet. 1993; 4:332-3. doi: 10.1038/ng0893-332.

31. Wang YD, Li SJ, Liao JX. Inhibition of glucose transporter 1 (GLUT1) chemosensitized head and neck cancer cells to cisplatin. Technol Cancer Res Treat. 2013; 12:525-35. doi: 10.7785/tcrt.2012.500343.

32. McBrayer SK, Cheng JC, Singhal S, Krett NL, Rosen ST, Shanmugam M. Multiple myeloma exhibits novel dependence on GLUT4, GLUT8, and GLUT11: implications for glucose transporter-directed therapy. Blood. 2012; 119:4686-97. doi: 10.1182/blood-2011-09-377846.

33. Bhattacharya B, Mohd Omar MF, Soong R. The Warburg effect and drug resistance. Br J Pharmacol. 2016; 173:970-9. doi: 10.1111/bph.13422.

34. Merkulova T, Dehaupas M, Nevers MC, Creminon C, Alameddine H, Keller A. Differential modulation of alpha, beta and gamma enolase isoforms in regenerating mouse skeletal muscle. Eur J Biochem. 2000; 267:3735-43.

35. Bai Z, Ye Y, Liang B, Xu F, Zhang H, Zhang Y, Peng J, Shen D, Cui Z, Zhang Z, Wang S. Proteomics-based identification of a group of apoptosis-related proteins and biomarkers in gastric cancer. Int J Oncol. 2011; 38:375-83. doi: 10.3892/ijo.2010.873.

36. Liu YQ, Huang ZG, Li GN, Du JL, Ou YP, Zhang XN, Chen TT, Liang QL. Effects of alpha-enolase (ENO1) overexpression on malignant biological behaviors of AGS cells. Int J Clin Exp Med. 2015; 8:231-9.

37. Song Y, Luo Q, Long H, Hu Z, Que T, Zhang X, Li Z, Wang G, Yi L, Liu Z, Fang W, Qi S. Alpha-enolase as a potential cancer prognostic marker promotes cell growth, migration, and invasion in glioma. Mol Cancer. 2014; 13:65. doi: 10.1186/1476-4598-13-65.

38. Tu SH, Chang CC, Chen CS, Tam KW, Wang YJ, Lee CH, Lin HW, Cheng TC, Huang CS, Chu JS, Shih NY, Chen LC, Leu SJ, et al. Increased expression of enolase alpha in human breast cancer confers tamoxifen resistance in human breast cancer cells. Breast Cancer Res Treat. 2010; 121: 539-53. doi: 10.1007/s10549-009-0492-0.

39. Fu QF, Liu Y, Fan Y, Hua SN, Qu HY, Dong SW, Li RL, Zhao MY, Zhen Y, Yu XL, Chen YY, Luo RC, Li R, et al. Alpha-enolase promotes cell glycolysis, growth, migration, and invasion in non-small cell lung cancer through FAKmediated PI3K/AKT pathway. J Hematol Oncol. 2015; 8:22. doi: 10.1186/s13045-015-0117-5.

40. Tsai ST, Chien IH, Shen WH, Kuo YZ, Jin YT, Wong TY, Hsiao JR, Wang HP, Shih NY, Wu LW. ENO1, a potential prognostic head and neck cancer marker, promotes transformation partly via chemokine CCL20 induction. Eur J Cancer. 2010; 46:1712-23. doi: 10.1016/j.ejca.2010.03.018. 
41. Zhao M, Fang W, Wang Y, Guo S, Shu L, Wang L, Chen Y, Fu Q, Liu Y, Hua S, Fan Y, Liu Y, Deng X, et al. Enolase-1 is a therapeutic target in endometrial carcinoma. Oncotarget. 2015; 6:15610-27. doi: 10.18632/oncotarget.3639.

42. Niccolai E, Cappello P, Taddei A, Ricci F, D’Elios MM, Benagiano M, Bechi P, Bencini L, Ringressi MN, Coratti A, Cianchi F, Bonello L, Di Celle PF, et al. Peripheral ENO1specific $\mathrm{T}$ cells mirror the intratumoral immune response and their presence is a potential prognostic factor for pancreatic adenocarcinoma. Int J Oncol. 2016; 49:393-401. doi: 10.3892/ijo.2016.3524.

43. Principe M, Ceruti P, Shih NY, Chattaragada MS, Rolla S, Conti L, Bestagno M, Zentilin L, Yang SH, Migliorini P, Cappello P, Burrone O, Novelli F. Targeting of surface alpha-enolase inhibits the invasiveness of pancreatic cancer cells. Oncotarget. 2015; 6:11098-113. doi: 10.18632/ oncotarget.3572.

44. Zhu X, Miao X, Wu Y, Li C, Guo Y, Liu Y, Chen Y, Lu X, Wang Y, He S. ENO1 promotes tumor proliferation and cell adhesion mediated drug resistance (CAM-DR) in NonHodgkin's Lymphomas. Exp Cell Res. 2015; 335:216-23. doi: 10.1016/j.yexcr.2015.05.020.

45. Filipp FV. Cancer metabolism meets systems biology: Pyruvate kinase isoform PKM2 is a metabolic master regulator. J Carcinog. 2013; 1214. doi: 10.4103/14773163.115423.

46. Seton-Rogers S. Cancer metabolism: feed it forward. Nat Rev Cancer. 2011; 11:461. doi: 10.1038/nrc3094.

47. Kwon OH, Kang TW, Kim JH, Kim M, Noh SM, Song KS, Yoo HS, Kim WH, Xie Z, Pocalyko D, Kim SY, Kim YS. Pyruvate kinase M2 promotes the growth of gastric cancer cells via regulation of $\mathrm{Bcl}-\mathrm{xL}$ expression at transcriptional level. Biochem Biophys Res Commun. 2012; 423:38-44. doi: 10.1016/j.bbrc.2012.05.063.

48. Zhao Y, Liu H, Liu Z, Ding Y, Ledoux SP, Wilson GL, Voellmy R, Lin Y, Lin W, Nahta R, Liu B, Fodstad O, Chen J, et al. Overcoming trastuzumab resistance in breast cancer by targeting dysregulated glucose metabolism. Cancer Res. 2011; 71:4585-97. doi: 10.1158/0008-5472. CAN-11-0127.

49. Mathupala SP, Ko YH, Pedersen PL. Hexokinase II: cancer's double-edged sword acting as both facilitator and gatekeeper of malignancy when bound to mitochondria. Oncogene. 2006; 25:4777-86. doi: 10.1038/sj.onc.1209603.

50. Pastorino JG, Shulga N, Hoek JB. Mitochondrial binding of hexokinase II inhibits Bax-induced cytochrome c release and apoptosis. J Biol Chem. 2002; 277:7610-8. doi: 10.1074/jbc.M109950200.

51. Ray R, Miller DM. Cloning and characterization of a human c-myc promoter-binding protein. Mol Cell Biol. 1991; 11: 2154-61.

52. Capello M, Ferri-Borgogno S, Riganti C, Chattaragada MS, Principe M, Roux C, Zhou W, Petricoin EF, Cappello P, Novelli F. Targeting the Warburg effect in cancer cells through ENO1 knockdown rescues oxidative phosphorylation and induces growth arrest. Oncotarget. 2016; 7:5598-612. doi: 10.18632/oncotarget.6798.

53. Lu H, Forbes RA, Verma A. Hypoxia-inducible factor 1 activation by aerobic glycolysis implicates the Warburg effect in carcinogenesis. J Biol Chem. 2002; 277:23111-5. doi: 10.1074/jbc.M202487200.

54. Frolova O, Samudio I, Benito JM, Jacamo R, Kornblau SM, Markovic A, Schober W, Lu H, Qiu YH, Buglio D, McQueen T, Pierce S, Shpall E, et al. Regulation of HIFlalpha signaling and chemoresistance in acute lymphocytic leukemia under hypoxic conditions of the bone marrow microenvironment. Cancer Biol Ther. 2012; 13:858-70. doi: 10.4161/cbt.20838.

55. Tran Q, Lee H, Park J, Kim SH, Park J. Targeting Cancer Metabolism - Revisiting the Warburg Effects. Toxicol Res. 2016; 32:177-93. doi: 10.5487/TR.2016.32.3.177.

56. Chen S, Cai J, Zhang W, Zheng X, Hu S, Lu J, Xing J, Dong Y. Proteomic identification of differentially expressed proteins associated with the multiple drug resistance in methotrexate-resistant human breast cancer cells. Int J Oncol. 2014; 45:448-58. doi: 10.3892/ijo.2014.2389.

57. Zhang H, Tang J, Li C, Kong J, Wang J, Wu Y, Xu E, Lai M. MiR-22 regulates 5-FU sensitivity by inhibiting autophagy and promoting apoptosis in colorectal cancer cells. Cancer Lett. 2015; 356:781-90. doi: 10.1016/j.canlet.2014.10.029.

58. Pandey AK, Zhang Y, Zhang S, Li Y, Tucker-Kellogg G, Yang H, Jha S. TIP60-miR-22 axis as a prognostic marker of breast cancer progression. Oncotarget. 2015; 6:41290-306. doi: 10.18632/oncotarget.5636.

59. Zhang J. microRNA-22, downregulated in hepatocellular carcinoma and correlated with prognosis, suppresses cell proliferation and tumourigenicity. British Journal of Cancer. 2010; 103:1215-20.

60. Yang F, Hu Y, Liu HX, Wan YJ. MiR-22-silenced cyclin A expression in colon and liver cancer cells is regulated by bile acid receptor. Journal of Biological Chemistry. 2015; 290:6507.

61. Wang W, Li F, Zhang Y, Tu Y, Yang Q, Gao X. Reduced expression of miR-22 in gastric cancer is related to clinicopathologic characteristics or patient prognosis. Diagn Pathol. 2013; 8:102. doi: 10.1186/1746-1596-8-102.

62. Tang H, Kong Y, Guo J, Tang Y, Xie X, Yang L, Su Q, Xie X. Diallyl disulfide suppresses proliferation and induces apoptosis in human gastric cancer through Wnt-1 signaling pathway by up-regulation of miR-200b and miR-22. Cancer letters. 2013; 340:72-81.

63. Guo MM, Hu LH, Wang YQ, Chen P, Huang JG, Lu N, He JH, Liao CG. miR-22 is down-regulated in gastric cancer, and its overexpression inhibits cell migration and invasion via targeting transcription factor Sp1. Med Oncol. 2013; 30:542. doi: 10.1007/s12032-013-0542-7.

64. Zuo QF, Cao LY, Yu T, Gong L, Wang LN, Zhao YL, Xiao B, Zou QM. MicroRNA-22 inhibits tumor growth and 
metastasis in gastric cancer by directly targeting MMP14 and Snail. Cell Death Dis. 2015; 6:e2000. doi: 10.1038/ cddis.2015.297.

65. Sibbesen NA, Kopp KL, Litvinov IV, Jønson L, WillerslevOlsen A, Fredholm S, Petersen DL, Nastasi C, Krejsgaard T, Lindahl LM. Jak3, STAT3, and STAT5 inhibit expression of miR-22, a novel tumor suppressor microRNA, in cutaneous T-Cell lymphoma. Oncotarget. 2015; 6:20555. doi: 10.18632/oncotarget.4111.
66. Shen Q, Yao Q, Sun J, Feng L, Lu H, Ma Y, Liu L, Wang F, Li J, Yue Y, Jin H, Wang X. Downregulation of histone deacetylase 1 by microRNA-520h contributes to the chemotherapeutic effect of doxorubicin. FEBS Lett. 2014; 588:184-91. doi: 10.1016/j.febslet.2013.11.034. 